\title{
Modeling of double emulsions using population balance equations
}

\author{
Behnam Khadem ${ }^{1}$, Nida Sheibat-Othman ${ }^{1 *}$ \\ ${ }^{1}$ University of Lyon, Université Claude Bernard Lyon 1, CNRS, LAGEP UMR 5007, F-69100, \\ Villeurbanne, France \\ "Corresponding author: nida.otham@univ-lyon1.fr
}

\begin{abstract}
Double emulsions are widely spread in a number of applications, such as food, cosmetics and pharmaceutics. They are usually prepared in two steps, comprising the preparation of a first emulsion that is in a second step introduced in an external continuous phase. A number of phenomena may occur during the second step including breakage, coalescence, and escape that is aimed to be reduced to keep high the encapsulation efficiency. Suitable models of these phenomena are proposed in this work and incorporated into a population balance model (PBM) to allow predicting the evolution of the droplet size distribution (DSD) of the external macrodroplets as well as the release rate. During the considered short preparation time and the slow molecular diffusion of the encapsulated salt, the release rate was assumed to be mainly governed by the leakage of internal droplets, i.e. their release due to the breakage of the macro-droplets. The proposed leakage model is thus described as a function of the breakage rate of the macro-droplets. The model parameters involved in the different sub-models of the PBMs (breakup and coalescence kernels, leakage) were identified in experiments of W/O/W double emulsions prepared using a rotor stator. Then, the model was validated under various key process conditions, such as the internal water fractions (10 - 40\%) and stirring rate. The dependence of the leakage parameter on the concentration of salt was also investigated. The macro-DSD was measured by Laser diffraction while the leakage rate was monitored by conductivity measurements.
\end{abstract}

\section{Keywords}

Double emulsions; Modelling; Population balance model; Leakage; Coagulation; Breakage. 


\section{Introduction}

Double emulsions (also called liquid membrane systems) consist of small droplets of one fluid suspended in larger droplets of a second immiscible fluid. They can be of two major types: water-in-oil-in-water (W/O/W) or oil-in-water-in-oil (O/W/O) double emulsions. Since their first observation by Seifriz et al. (1925) [1], double emulsions found a wide range of applications in the chemical, petrochemical, polymer, waste water treatment, food, cosmetic and pharmaceutical industries. Examples of these applications are extraction of organic and inorganic compounds [2], preparation of low-fat foods [3] and drug delivery [4]. In these applications, the quality of the final product is determined by the micro- (i.e. internal) and macro- (i.e. external) droplet size distribution (DSD) [5] and the release rate of the encapsulated ingredients to the external phase $[2,4,6]$.

The two-step method, firstly reported by Matsumoto et al. (1976) [7], represents the most common way to prepare double emulsions. In this method, the first step consists of mixing the internal phase with the intermediate phase under high shear rate to realize small microdroplets. The second step consists of dispersing this internal emulsion into a continuous external phase. A lower mixing intensity and shorter time are employed in the second step in order to reduce the release of the internal phase. Bigger external (macro-) droplets are thus produced compared to the internal (micro-) droplets.

Different destabilization pathways may occur during the second preparation step of double emulsions, as well as during storage, such as macro-droplet breakage and coalescence, Ostwald ripening, swelling or shrinkage, leakage of micro-droplets (i.e. escape due to breakage) [8-13], and over-swelling (leading to explosion) [2,5,6,13-16]. Such a high number of simultaneous phenomena taking place in the system represent the main difficulty in modeling this system. Another difficulty is related to the lack of experimental methods allowing to accurately measure the internal DSD. Finally, both the micro- and macro-droplets are usually distributed in size.

In terms of modeling the evolution of the droplet size, a number of works have been performed regarding single emulsions, either using stationary models that describe only a mean diameter 
[17-19] or using PBM $[20,21]$. Some stationary correlations were also applied to model double emulsions [22-25].

In terms of modelling the extraction rate from double emulsions, few works concerned the escape in the absence of breakage, which would be interesting during storage but is not sufficient during the preparation of the double emulsion. For instance, Ho et al. (1982) [26] developed a diffusion model assuming micro- and macro-droplets to be of uniform size and in the absence of breakage and over-swelling/explosion of macro-droplets. Kang et al. (2016) [27] developed an escape model based on the dewetting phenomenon during storage of double emulsions. Pays et al. (2001) [28] and Chávez-Páez et al. (2012) [14] proposed an escape model during storage based on the coalescence of micro-droplets with the external aqueous phase. Few other works concerned modelling escape during preparation. For instance, Klahn et al. (2002) [29] proposed a model to describe micro-droplet escape in simple shear flow regime. Mukhopadhyay et al. (2008) [11] proposed a model to describe osmotic and occlusion modes of swelling of double-emulsions assumed to have a core-shell structure, and a leakage model of the internal phase that was assumed proportional to the thickness of the membrane. Okazaki (1992) [30] proposed a leakage correlation as a function of the energy dissipation rate, viscosity and osmotic pressure. Shere and Cheung (1988) [16] proposed a model to describe leakage assuming macro-droplet rupture to be the main mechanism responsible for micro-droplet leakage, while the internal substance was assumed to have negligible diffusivity through the membrane during the preparation time. A summary of some models describing the release rate during preparation can be found in table 1.

The objective of this work is to develop a model that describes micro-droplet escape during the second preparation step of the double emulsion, where the micro-and macro-droplets are not of uniform size and where macro-droplets may undergo breakage and coalescence. These phenomena can be described by considering population balance models (PBM) of the internal and external droplets. In turbulent systems, these phenomena are the consequence of the mechanical operating conditions, such as the energy dissipation rate, and physical properties like viscosity, density and the interfacial tension. However, while a number of kernels were proposed to describe breakage and coalescence of simple emulsions in turbulent systems 
$[20,21]$, a specific attention is required when applying these kernels to double emulsions, as a number of properties of the dispersed phase change when the dispersed phase itself becomes an emulsion, such as its density, viscosity and surface tension [24,31]. Finally, the escape model is required to be combined to breakage and coalescence of the macro-droplets within the population balance model.

In this work, rotor stator is used in the first and second emulsification steps to prepare W/O/W double emulsions. A number of key process parameters were investigated during the preparation of the double emulsions, namely, the fraction of internal water, the stirring rate in the second preparation step and the fraction of salt. The size of macro-droplets was monitored offline by laser diffraction and the release of salt by conductivity measurements.

\section{Experimental}

\subsection{Materials}

The materials used to prepare the W/O/W double emulsions are Mineral oil (Fisher Scientific ${ }^{\mathrm{TM}}$ ), Span 80 (Alfa Aesar) as hydrophobic internal emulsifier, Tween 80 (Fisher Scientific $^{\mathrm{TM}}$ ) as hydrophilic external emulsifier, Sodium Chloride as tracer and regulator of osmotic pressure and Millipore water (resistivity $\approx 18.2 \mathrm{~m} \Omega . \mathrm{cm}$ ).

\subsection{Double emulsion preparation}

W/O/W double emulsions were prepared at room temperature using a two-step method (see figure 1). In the first step, the $\mathrm{NaCl}$ aqueous solution was dispersed in the oil phase - consisting of oil in which Span 80 is dissolved - and mixed using an IKA T 25 digital ULTRA-TURRAX ${ }^{\circledR}$ at $12000 \mathrm{rpm}$ for $4 \mathrm{~min}$. In the second step, this primary emulsion was dispersed in an external aqueous phase - consisting of water in which Tween 80 is dissolved - and mixed using the ULTRA-TURRAX $^{\circledR}$ at $3400 \mathrm{rpm}$ for 1-16 min. The fractions of these materials are shown in Table 2. The employed ULTRA-TURAX was equipped with the dispersing elements S25N-10G and S25N-18G for mixing the first and second emulsions respectively. 


\subsection{Droplet size measurement}

The size of the micro-droplets was measured right after the first step of preparation by means of dynamic light scattering (Malvern Zetasizer Nano ZS ${ }^{\circledR}$ ). Then, samples were taken every one minute during the second preparation step and the size distribution of the macro-droplets was analyzed using laser diffraction (Malvern Mastersizer $3000^{\circledR}$ ).

\subsection{Conductivity measurements}

The released amount of $\mathrm{NaCl}$ was monitored by measuring the conductivity of the samples, taken every one minute during the second preparation step, using a CDM210 Conductivity Meter (MeterLab $\left.{ }^{\circledast}\right)$. The released amount was estimated based on a predetermined calibration curve. Two calibration methods were evaluated and found equivalent, either by dispersing different salt concentrations in pure water or by dispersing the salt in a single $\mathrm{O} / \mathrm{W}$ emulsion instead of water, thus indicating no effect of the oil on the measurement in the employed concentration range.

\section{Modeling}

Double emulsions consist of an emulsion inside another emulsion. Thus, there are two dispersed phases. The internal dispersed phase consists of water droplets dispersed into the oil phase, and will be referred to as micro-droplets hereafter. The external dispersed phase consists of the first emulsion dispersed into water, and will be referred to as macro-droplets. Each of these dispersions is distributed in size, and can thus be described by a population balance.

\subsection{Population balance models}

The general PBM of size distributed systems [33,34] can be applied for both the macro- and micro-droplets during the second preparation step of the double emulsion. On one hand, macro-droplets might undergo breakage, coalescence and swelling that might lead to overswelling and explosion, which leads to the following balance of the number density distribution of macro-droplets, $n_{M}$ (number per $\mathrm{m}^{-3}$ of macro-droplet size): 
$\frac{\partial n_{M}(t, v)}{\partial t}+\frac{\partial\left(S_{M}(t, v) n_{M}(t, v)\right)}{\partial x}=\mathfrak{R}_{B r}+\mathfrak{R}_{C o}+\mathfrak{R}_{E x p}$

On the other hand, micro-droplets can be assumed to undergo mainly leakage, as the external mixing is supposed to cause no breakage and very little coalescence within the considered preparation time and energy $[35,36]$. Thus, the number density of micro-droplets $\left(n_{m}\right)$ can be obtained by:

$\frac{\partial n_{m}(t, v)}{\partial t}+\frac{\partial\left(s_{m}(t, v) n_{m}(t, v)\right)}{\partial x}=\Re_{C o}^{m}-\Re_{\text {Leak }}$

Where $v$ is the droplet volume, $\mathbb{S}$ the swelling or shrinkage rates due to osmotic pressure difference or diffusion by Oswald ripening, $\mathfrak{R}_{\mathrm{Br}}$ the breakage rate, $\mathfrak{R}_{C o}$ the coalescence rate, $\mathfrak{R}_{\text {Exp }}$ the explosion rate (due to over-swelling) and $\mathfrak{R}_{\text {Leak }}$ is the internal droplet leakage rate (number. $\mathrm{m}^{-3} \cdot \mathrm{s}^{-1}$ ). The indices $m$ and $M$ refer to micro- and macro-droplets respectively.

Due to the short time of the second step of the double emulsion preparation, swelling of microor macro-droplets can be considered to be negligible, and therefore over-swelling leading to explosion is negligible. Oswald ripening is also negligible during the preparation period due to the low solubility of each phase in the other. With these assumptions, Eqs. (1-2) become:

$\frac{\partial n_{M}(t, v)}{\partial t}=B_{B r}(t, v)-D_{B r}(t, v)+B_{C o}(t, v)-D_{C o}(t, v)$

$\frac{\partial n_{m}(t, v)}{\partial t}=-\Re_{\text {Leak }}$

Where the birth $(B)$ and death $(D)$ terms for breakage and coalescence are as follows [33,34]:

$B_{B r}(t, v)=\int_{v}^{\infty} b(v, \varepsilon) \Gamma(t, \varepsilon) n(t, \varepsilon) d$

$D_{B r}(t, v)=\Gamma(v) n(t, \varepsilon)$

$B_{c o}(t, v)=\frac{1}{2} \int_{0}^{v} \beta(v, v-\varepsilon) n(t, v-\varepsilon) n(t, \varepsilon) d \varepsilon$

$D_{c o}(t, v)=n(t, v) \int_{0}^{\infty} \beta(v, \varepsilon) n(t, \varepsilon) d \varepsilon$

\subsection{Leakage rate}

The leakage is defined as the escape of micro-droplets upon breakage of the macro-droplets. The leakage causes a decrease in the volume of the encapsulated micro-droplets and so in the 
macro-droplets' volume. Considering a constant micro-droplet volume fraction in the macrodroplets, independently of their size, one may write $\frac{d V_{M}}{d t}=\frac{d V_{m}}{d t}$, with $V_{M}=V_{m}+V_{o i l}$.

The escape of micro-droplets leads to the release of salt that they contain. This mechanism is assumed to represent the main mechanism of release of salt, since the diffusion of salt into the oil phase is slow. Therefore, when escape occurs, only the total volume of micro-droplets $\left(V_{m}\right)$ decreases while the concentration of salt in the micro-droplets $\left(C_{m}\right)$ remains constant (i.e. $\left.\frac{d C_{m}}{d t}=0\right)$. Therefore, the material balance of salt in the micro-droplets becomes:

$\frac{d\left(V_{m} C_{m}\right)}{d t}=C_{m} \frac{d V_{m}}{d t}=-C_{m} Q_{L}$

Where $Q_{L}$ is the volumetric flowrate of micro-droplet given by:

$Q_{L}=-\frac{d V_{m}}{d t}=-\frac{d V_{M}}{d t}=\int_{0}^{\infty} \Re_{\text {Leak }}\left(t, v_{m}\right) v_{m} d v_{m}$

Based on experimental observations, it can be assumed that micro-droplet escape is governed by the breakage rate of the macro-droplets, as also reported by $[8,16,37]$. This assumption is valid only during the preparation of macro-droplet, as during storage the escape may occur via other pathways mentioned above, like diffusion or swelling-breakdown. It is therefore reasonable to write the leakage rate as a function of the change in the surface of macrodroplets and the volume fraction of the internal phase, as follows:

$Q_{L}=k_{L} \frac{V_{m}}{V_{M}} \int_{0}^{\infty} \pi r_{M}^{2} \Re_{B r}\left(t, v_{M}\right) d v_{M}$

Where $k_{L}$ is the leakage rate coefficient (in meter) and $r_{M}$ is the macro-droplet radius.

By substitution into equation 9 , the number of moles of salt in the micro-droplets $\left(N_{m}=V_{m} C_{m}\right)$ can be calculated by:

$\frac{d N_{m}}{d t}=-k_{L} \frac{N_{m}}{V_{M}} \int_{0}^{\infty} \pi r_{M}^{2} \cdot \Re_{B r}\left(t, v_{M}\right) d v_{M}$

\subsection{Energy dissipation in high shear devices}

The energy dissipation rate is one of the key process parameters that is required in the breakage and coalescence kernels. In rotor-stator devices like ULTRA-TURRAX ${ }^{\circledR}$ the energy 
dissipation in the continuous phase can be calculated using the power equation, similarly to stirred tanks [19]:

$\varepsilon_{c}=\frac{N_{P} \omega_{R}^{3} D_{R}^{5}}{V}$

Where $\omega_{R}[r p s]$ is the rotational speed of the rotor, $D_{R}$ the rotor diameter, $N_{P}$ the power number and $\mathrm{V}$ is the volume of the mixed media.

In turbulent flow regime, the power number of high shear rotor stator mixers is constant and is in the range of $1.4-3$ for different geometries [19]. In this work, a power number equal to 1.7 was used, as determined by Padron (2001) [38].

\subsection{Breakage kernel}

During the second step of double emulsion preparation, a high shear rate is employed by means of Ultra-Turrax, and therefore the fluid dynamics are in a turbulent flow regime. The breakage and coalescence kernels developed for turbulent flows should therefore be used. The turbulent energy is thus the driving force for breakage of the macro-droplets while the viscous and surface forces are the driving forces for stabilization. In this regard, Alopaeus et al. [39] proposed a breakage kernel that they employed on a compartmentalized stirred tank reactor:

$\Gamma(v)=C_{1} \varepsilon_{e f f}^{\frac{1}{3}} \operatorname{erfc}\left(\sqrt{\frac{C_{2} \sigma_{\text {disp }}}{\rho_{c} \varepsilon_{e f f}^{\frac{2}{3}} v^{\frac{5}{9}}}+\frac{C_{3} \mu_{\text {disp }}}{\sqrt{\rho_{c} \rho_{\text {disp }} \varepsilon_{e f f}^{\frac{1}{3}} v^{\frac{4}{9}}}}}\right)$

Where $C_{1}, C_{2}$ and $C_{3}$ are the breakage rate coefficients, $v$ the droplet volume, $\sigma$ the interfacial tension, $\varepsilon_{e f f}$ the effective energy dissipation rate of the dispersion, $\mu_{d i s p}$ and $\mu_{c}$ are the dispersed and continues phase viscosities respectively, $\rho_{\text {disp }}$ and $\rho_{c}$ are the dispersed and continues phase densities respectively and erfc stands for the complementary error function. This kernel was used by Qin et al. [40] to model the emulsification in a rotor-stator mixer, within a coupled CFD-PBM framework.

To model the daughter size distribution, the normal distribution was selected [41]:

$b\left(v_{i}, v_{j}\right)=\frac{2 c}{v_{j} \sqrt{2 \pi}} \exp \left(-\frac{\left(v_{i}-0.5 v_{j}\right)^{2}(2 c)^{2}}{2 v_{j}^{2}}\right)$ 
Where $c$ is a constant which is equal to 3 .

\subsection{Coalescence kernel}

Binary coalescence of two droplets of volumes $v_{i}$ and $v_{j}$ can be defined as the product of collision frequency, $h\left(v_{i}, v_{j}\right)$, and coalescence efficiency, $\lambda\left(v_{i}, v_{j}\right)[42]$ :

$\beta\left(v_{i}, v_{j}\right)=h\left(v_{i}, v_{j}\right) \lambda\left(v_{i}, v_{j}\right)$

The collision frequency depends on the shear during preparation while it depends on the Brownian motion during storage. Coulaloglou and Tavlarides [42] proposed a binary collision frequency for turbulent conditions, that was later-on slightly revised as follows (see for instance [43-46]):

$h\left(V_{i}, V_{j}\right)=C_{4} \varepsilon_{e f f}^{\frac{1}{3}}\left(v_{i}^{1 / 3}+v_{j}^{1 / 3}\right)^{2}\left(v_{i}^{2 / 9}+v_{j}^{2 / 9}\right)^{1 / 2}$

To describe the coalescence efficiency, Coulaloglou and Tavlarides [42] proposed to use the film drainage theory:

$\lambda\left(v_{i}, v_{j}\right)=\exp \left(-\frac{t_{d}}{t_{c}}\right)=\exp \left[-\frac{C_{5} \mu_{c} \rho_{c} \varepsilon_{e f f}}{\sigma_{\text {disp }}^{2}}\left(\frac{v_{i}^{1 / 3} v_{j}^{1 / 3}}{v_{i}^{1 / 3}+v_{j}^{1 / 3}}\right)^{4}\right]$

Where $t_{d}$ is the drainage time and $t_{c}$ the contact time.

It can be seen that the coalescence efficiency depends on the surface tension. However, an excess amount of surfactant is employed in this work, thus ensuring full coverage of the microand macro-droplets' surface area during all the preparation stages. Therefore, the surface tension was the same in all experiments.

\subsection{Properties of the dispersion}

It is important to take into account the effect of the presence of the dispersed phase on the properties of the dispersion and to use these apparent properties in the population balance, rather than using those of the pure phases.

For instance, the apparent viscosity of the liquid-liquid dispersion can be obtained by the model of Vermeulen (1955) [47]: 
$\mu_{\text {disp }}=\frac{\mu_{c}}{1-\phi_{m}}\left(1+1.5 \phi_{m} \frac{\mu_{d}}{\mu_{d}+\mu_{c}}\right)$

Similarly, the density of macro-droplet changes due to the presence of micro-droplets dispersion by the model of Miller and Mann (1944) [48]:

$\rho_{\text {disp }}=\phi_{m} \rho_{d}+\left(1-\phi_{m}\right) \rho_{c}$ 20

Also, the increase in the dispersed phase fraction is known to damp the continues phase energy dissipation [42]:

$\varepsilon_{\text {eff }}=\frac{\varepsilon_{c}}{\left(1+\phi_{M}\right)^{3}}$

Finally, the interfacial tension of the macro-droplets may also be affected by the presence of micro-droplets, as the change in the work required to strain a pure-oil droplet may be different from the required work for a droplet containing other droplets [31]. However, the experimental and simulation results indicated a negligible effect, so the interfacial tension between water and oil droplet - not containing micro-droplets - was implemented hereafter.

\subsection{Numerical solution}

The finite volume discretization scheme was used to solve the population balance equations. This method was firstly developed by Filbet and Laurençot (2004) [49] for pure coalescence in which the PBM was reformulated into a mass distribution, $g(t, v)=v n(t, v)$. Then, Kumar et al. [50] extended the model for combined breakage and coalescence.

$\frac{\partial g(t, v)}{\partial t}=$

$-\frac{\partial}{\partial v}\left(\int_{0}^{v} \int_{v-u}^{v_{\max }} u \beta(u, v) n(t, u) n(t, v) d v d u\right)+\frac{\partial}{\partial v}\left(\int_{v}^{\infty} \int_{0}^{v} u b\left(u, v^{\prime}\right) \Gamma\left(v^{\prime}\right) n\left(t, v^{\prime}\right) d u d v^{\prime}\right)$

By discretizing the mass balance across the cell boundaries $\left[i+\frac{1}{2}, i-\frac{1}{2}\right]$ :

$\frac{\Delta g_{i}}{\Delta t}=-\frac{\left(J_{i+\frac{1}{2}}^{C o}+J_{i+\frac{1}{2}}^{B r}-J_{i-\frac{1}{2}}^{C o}-J_{i-\frac{1}{2}}^{B r}\right)}{v_{i+1 / 2}-v_{i-1 / 2}}$

With the mass fluxes:

$J_{i+\frac{1}{2}}^{B r}=-\sum_{k=i+1}^{I} g_{k} \int_{\Lambda_{k}} \frac{\Gamma(v)}{v} d v \int_{0}^{v_{i+1 / 2}} u b\left(u, v_{k}\right) d u$ 
$J_{i+\frac{1}{2}}^{C o}=\sum_{k=1}^{i}\left(\sum_{j=\alpha_{i, k}}^{I} \int_{\Lambda_{j}} \frac{\beta\left(u, v_{k}\right)}{u} d u g_{i}+\int_{v_{i+1 / 2}-v_{k}}^{v_{\alpha_{i, k}-1 / 2}} \frac{\beta\left(u, v_{k}\right)}{u} d u g_{\alpha_{i, k-1}}\right)$

Where $\alpha_{i, k}$ represents the index of each cell, such that $v_{i+1 / 2}-v_{k} \in \Lambda_{\alpha_{i, k-1}}$.

\section{Results and discussions}

Different process parameters were investigated during the preparation of double emulsions and the model robustness was evaluated. These parameters include the internal water fraction, the stirring rate and time and the salt concentration (see Table 2).

For each experiment, the double emulsion was first shaken by hand to make a uniform premix and a sample was taken to measure the initial DSD, which is used as an input for the simulations. Then, mixing by the rotor stator was employed following the stirring rate and times indicated in the table 2 , and samples were taken every one minute to measure the macro-DSD and the conductivity. A typical optical image of the double emulsion just after preparation is shown in Figure 2 that clearly indicates the presence of internal droplets. Figure $2 \mathrm{~B}$ shows that some of the micro-droplets can reach a diameter up to $6 \mu \mathrm{m}$. Using Nano-ZS, the DSD of microdroplets measured just after the first step, i.e. the primary emulsion (Figure 3). The mean droplet diameter was around $1 \mu \mathrm{m}$, however the figure shows that the droplet size can be as high as $1.5 \mu \mathrm{m}$. Therefore, the microscopic image is showing comparable results to the DSD obtained by Nano-ZS, but slightly higher sizes could be detected. This may indicate the occurrence, during the second step, of either some coalescence as previously reported by Hindmarsh et al. [36], or swelling, but that seem to be minor.

\subsection{Parameter identification}

The optimization procedure was done using the following objective function, and by employing the nonlinear solvers "Isqnonlin" and "fmincon" in a "MultiStart class" global optimization function of Matlab ${ }^{\circledR}$ :

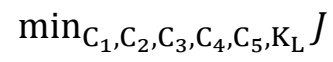

with 


$$
J=\sum_{2 \text { experiments }}\left(\sum_{\text {sample }^{\circ}}\left(\sum_{\mathrm{t}=1,2,3,4,16 \mathrm{~min})}\left|n_{\mathrm{M}}^{\text {Model }}(t, v)-n_{\mathrm{M}}^{\mathrm{Exp}}(t, v)\right|+\left|C_{\mathrm{m}}^{\text {Model }}-C_{\mathrm{m}}^{\text {Exp }}\right|\right)\right.
$$

with $\left[\mathrm{C}_{1}, \mathrm{C}_{2}, \mathrm{C}_{3}, \mathrm{C}_{4}, \mathrm{C}_{5}, \mathrm{~K}_{\mathrm{L}}\right] \in[0, \infty]$.

Two experiments, with different energy dissipation rates (3 400 and $5600 \mathrm{rpm}$ ) and internal water fractions ( $\phi_{m}=20 \%$ and $10 \%$, respectively), were used to identify the model parameters. Then, the obtained parameters were used to predict the evolution of the DSD of macrodroplets as well as the leakage rate while varying the process operating conditions.

The initial guess of the breakage and coalescence kernels $\left(C_{1}-C_{5}\right)$ was obtained by optimization of these coefficients alone without considering leakage. The obtained results were then used in order to optimize all the coefficients together $\left(C_{1}-C_{5}, K_{L}\right)$, including the leakage phenomena. This way was found to give a more robust parameter identification.

The obtained parameters are given in table 3 , and compared to some values from the literature. The breakage parameters $C_{2}$ and $C_{3}$ are respectively related to the ratio of surface tension and dispersed phase viscosity to the inertia. Increasing these parameters decreases the breakage probability. Lower values are obtained in the Ultra-Turrax compared to the stirred tank, thus indicating a higher breakage efficiency. This might be due to the higher energy dissipation and the induced shear on the droplets surface. Concerning the ratio of $C_{3}$ to $C_{2}$ (revealing the relative impact of the droplets viscosity), then it is much higher for Ultra-Turrax than for stirred tanks. This can be due to the smaller droplets produced in this case. Indeed, from Hinze (1955) [18] it can be deduced that for big droplets, the breakage phenomenon depends only on the ratio of energy dissipation to the surface force (i.e. $C_{2}$ ), while for smaller droplets it also depends on the dispersed phase viscosity (i.e. $\mathrm{C}_{3}$ ), as also supported by data from Narsimhan et al. [51] and Coulaloglou \& Tavlarides (1977) [42]. Concerning the value of $\mathrm{C}_{1}$, it is within the same range as for stirred tanks.

Regarding the coalescence parameters, higher values of $C_{4}$ are obtained with the Ultra-Turrax, thus indicating a higher collision frequency, due to the higher energy dissipation. Concerning $C_{5}$, the higher its value the lower is the coalescence efficiency (very high values of $C_{5}$ lead to a probability of zero). It appears that a higher coalescence efficiency is obtained in Ultra-Turrax, 
which can be due to the high shear, as for the breakage efficiency. The identifiability of $C_{5}$ was however argued for a low coalescence rate. Ribeiro et al. (2011) [53] indicated that when the overall coalescence rate is low, the parameter $C_{5}$ has a negligible influence, which justified the fact that different values were identified when changing the initial guess.

\subsection{Effect of the internal water fraction}

The effect of the internal water fraction was investigated in the first set of experiments over the range of $10 \%, 20 \%, 30 \%$ and $40 \%$ (Set 1 in table 2). Figure 4 shows an example of the model predictions of the DSD compared to the experimental results (Figure $4 \mathrm{~A}$ ) and the leakage rate (Figure 4B) that is represented by the fraction of the released salt. The figure indicates a good prediction capability of both models.

When plotting the different experiments of Set 1 together (Figure 5), it can be seen that when increasing the internal water fraction, the DSD moved towards bigger sizes while the leakage rate decreased slightly. This observation cannot be related to an enhanced coalescence phenomena, as the coalescence phenomena would not reduce the leakage rate. On the contrary, this seems to be due to a reduced breakage rate. Indeed, when increasing the internal water fraction, the viscosity of the macro-droplets is increased, following Vermeulen's relation (Eq. 19). This leads to a decrease in the breakage rate, following experimental observations and as expected from the used model (Eq. 14) [39]. With the decreased breakage rate, the leakage is also decreased, as observed by Figure 5B. It should be noted that the size of the internal droplets might also have an effect on the apparent viscosity of the globule (macro-droplet), but this parameter was not investigated in this work. In summary, increasing the internal water fraction leads to an increase in the macro-droplets viscosity, which decreases both the breakage and leakage rates. So, the observed effect seems to be due to a change in the effective viscosity of the globules.

\subsection{Effect of the stirring rate}

The stirring rate, as well as the type of rotor stator and the properties of the continuous phase all have a direct effect on the energy dissipation rate. In this section, the effect of the stirring rate on energy dissipation, and therefore on the breakage and leakage rates, is investigated 
(Set 2 in table 2). Using equation 13, the mean energy dissipation rate was calculated in these experiments to be $\varepsilon_{c}=0.405,1.8$ and $3.23 \mathrm{~W} \cdot \mathrm{kg}^{-1}$ for mixing rates of 3400,5600 and $6800 \mathrm{rpm}$ respectively. It is to be noted that the energy dissipation in the region between the rotor and stator is orders of magnitudes higher than these mean values, but only the average values are used in the kernel.

Figure 6 shows the model predictions compared to the experimental results when changing the energy dissipation. A good prediction of both the DSD and leakage rate is obtained under these conditions. It can be seen (Figure 6A) that when increasing the stirring rate the macro-droplet's size is decreased until equilibrium between breakage and coalescence is reached where no more decrease is observed. This is due to the fact that both phenomena are proportional to the energy dissipation rate.

Concerning the leakage fraction (Figure 6B), it increases when increasing the stirring rate, independently of the observed equilibrium in terms of droplet size. Indeed, even if equilibrium between breakage and coalescence is reached, leakage continues to occur proportionally to the breakage rate. This confirms the hypothesis of relating the leakage to the breakage rate, and not only to the macro-droplet size.

Figure 7 shows the typical evolution of the DSD with time in two experiments, with $\phi_{m}=$ $10 \%$ : Figure 7A at $3400 \mathrm{rpm}$ and Figure 7B at $5600 \mathrm{rpm}$. It can be seen that the equilibrium is reached very quickly in both cases, but smaller droplets are obtained when mixing at 5600 rpm.

\subsection{Effect of the salt concentration on leakage}

As the salt concentration is expected to modify the osmotic pressure and thus the stability of micro-droplets against leakage, then the leakage rate coefficient, $k_{L}$, is dependent on the salt concentration. It would thus be interesting to write this coefficient as a function of the concentration of salt, in order to generalize the proposed leakage model over a wide range of salt fractions, which can be done as follows:

$k_{L}=k_{L 0} C_{m}^{-\alpha}$ 
Where $k_{L 0}$ and $\alpha$ are the model parameters, that are supposed to be constant.

The effect of salt on leakage was investigated by changing the salt fraction over the range of $0.01 \%$ to $0.23 \%$ (Set 3 in table 2). Using the experimental leakage rate, the model parameters were identified to be $k_{L 0}=8.77 \times 10^{-6} \mathrm{~m}$ and $\alpha=2.54$.

Note that the presence of salt may also affect the physical stability of the macro-droplets, and thus the breakage or coalescence rates, as the Laplace pressure curvature can be counterbalanced by the salt as a result of osmotic pressure [54]. In this case, the salt contributes to the surface force. This effect was not considered in the model, as the surface tension was approximated to be the same in all experiments. Also, the difference between osmotic and Laplace pressure due to the addition of salt can lead to swelling of the micro- and macro-droplets, but this requires longer time periods to become significant, for instance during storage [54].

Figure $8 \mathrm{~A}$ shows the fraction of leaked number of micro-droplets as a function of the salt concentration, both experimentally and by the model. The double emulsions becomes more stable and better opposes leakage when increasing the salt concentration. A burst drop in leakage fraction is observed when increasing the salt concentration until reaching a negligible effect at the salt concentration of $20 \mathrm{~mol} \mathrm{~m}^{-3}\left(\phi_{\text {salt }}=0.05 \%\right)$. Okazaki et al. (1992) also observed that the osmotic pressure, or salt concentration, have an effect on leakage only over a specific concentration range of salt [30]. Figure $8 B$ shows the DSD of micro-droplets for different salt fractions. It can be seen that increasing the salt concentration leads to an increase in the micro-droplet size until a specific concentration limit, beyond which the droplets size decreases. This can be due to the salt effect on the spreading of surfactant on the interface, and thus on its stabilization potential. Note that the size of internal droplets is accounted for in the proposed leakage model.

\subsection{Comparison to equilibrium correlation}

As an evaluation of the methodology, the obtained mean diameter by PBM was compared to the Kolmogorov-Hinze correlation at equilibrium: 
Where $d_{32}$ is the Sauter mean diameter and $\mathrm{We}=\frac{\omega_{R}^{2} D_{\mathrm{R}}^{3} \rho_{\mathrm{c}}}{\sigma}$ is the Weber number. Figure 9 shows that the evolution of $d_{32}$ is proportional to $\mathrm{We}^{-0.6}$, as suggested by Kolmogorov-Hinze. This is because the kernel of Alopaeus et al. relies on similar assumptions as suggested by Kolmogorov and Hinze. The Weber number changes when changing the stirring rate and at $\mathrm{We}^{-0.6}=0.1$ different experiments were realized with different macro-droplet viscosities, where the macro-droplets contain different fractions of internal phases. It can be seen that the viscosity of the dispersed phase changes the slope, and it is required to be accounted for in the correlation. Note that while this correlation is simple to use, it is valid only at equilibrium and it only predicts a mean size, while the population balance allows for predicting the whole DSD as a function of time.

\section{Conclusions}

A combined population balance and leakage model is developed in order to predict the evolution of the macro-DSD and the leakage rate during the preparation of double emulsions. The methodology includes the adaptation of the breakage and coalescence kernels for double emulsions in order to account for the changes in the dispersion properties, such as the apparent density and viscosity. Moreover, a leakage model is proposed by assuming the breakage rate of macro-droplets to be the driving force for leakage. Finally, the leakage coefficient was described as a function of the salt concentration in order to generalize the model over a wide range of salt concentrations.

The obtained experimental results demonstrate the model validity over a wide range of experimental conditions. An effect of the internal phase fraction was observed on the viscosity of the macro-droplets which showed a direct effect on the breakage rate as well as the leakage fraction. A fast convergence of the macro-DSD to an equilibrium point between coalescence and breakage rates was observed. Increasing the stirring rate in the second step of preparation, and thus the energy dissipation, showed an increase in the leakage of salt, but a negligible effect on the macro-DSD that quickly reached equilibrium. The increase of the salt 
concentration was found to have an effect on the micro-DSD in a nonlinear way, which may be explained by an effect of salt on the stabilizer spreading. Increasing the salt fraction was also found to decrease the leakage rate until the volume fraction of $\phi_{\text {salt }}=0.05 \%$, beyond which no more effect of salt on the leakage rate could be observed.

The DSD and the leakage rate in double emulsions are the key parameters determining the final product properties. This study showed that an accurate estimation of these parameters can be achieved by using PBM and by employing operational and physical parameters which in turn helps to define an accurate leakage model. Such models are useful in different domains of double emulsions, like food, cosmetics and pharmaceutical industries, where increasing the encapsulation efficiency and ensuring the physical stability of droplet are of high importance. Double emulsions may also be employed as liquid membranes for solvent extraction, for instance in waste water treatment, where the proposed leakage model can be used. Finally, the methodology can be extended to other mixing devises by modifying the energy dissipation.

\section{Acknowledgement}

This work was funded by ModLife ITN. Grant agreement number 675251.

The authors would like to thank Professor Guoping Lian (UNILEVER, UK) for providing advises during this research.

\section{Nomenclature}

$b$ : Daughter size distribution [-]

$B:$ Birth term [-]

$C_{m}, C_{e x}$ : Salt concentration in the micro-droplets or in the external phase respectively $\left[\mathrm{mol} . \mathrm{m}^{-3}\right]$

$\mathrm{C}_{1}\left[\mathrm{~m}^{-\frac{2}{3}}\right], \mathrm{C}_{2}[-], \mathrm{C}_{3}[-]:$ Breakage rate constants

$\mathrm{C}_{4}[-], \mathrm{C}_{5}\left[\mathrm{~m}^{-2}\right]:$ Coalescence rate constants

$d$ : Droplet diameter $[\mathrm{m}]$ 
$d_{32}:$ Sauter mean diameter $[\mathrm{m}]$

$D$ : Death term in the PBM $[-]$

$D_{R}:$ Rotor diameter or stirrer diameter $[\mathrm{m}]$

$g(t, v)$ : Size distribution in volume density $\left[\mathrm{m}^{3} \mathrm{~m}^{-3}\right]$

$h$ : Collision frequency $\left[\mathrm{s}^{-1}\right]$

I: Total number of grid cells [-]

$J$ : Volumetric flux across cell boundary $\left[\mathrm{s}^{-1}\right]$

$\mathrm{K}_{\mathrm{L}}, \mathrm{K}_{\mathrm{L} 0}$ : Leakage rate constants [m]

$n(t, v)$ : number density [number per $\mathrm{m}^{-3}$ of droplet size]

$N_{m}$ : Number of moles of salt in the micro-droplets [mol]

$N_{P}$ : Stirrer power number [-]

$Q_{L}:$ Volumetric leakage flow rate $\left[\mathrm{m}^{3} \mathrm{~s}^{-1}\right]$

$r$ : Droplet radius $[\mathrm{m}]$

$\Re:$ Rate [number $\mathrm{m}^{-3} \mathrm{~s}^{-1}$ ]

$\Gamma$ : Breakage kernel $\left[\mathrm{s}^{-1}\right]$

S: Swelling rate $\left[\mathrm{m}^{3} \mathrm{~s}^{-1}\right]$

$t_{c}$ : Contact time $[\mathrm{s}]$

$t_{d}$ : Film drainage time [s]

$t_{1}, t_{2}$ : Mixing time of the first and second steps [min]

$u$ and $v$ : Droplet volume $\left[\mathrm{m}^{3}\right]$

$V$ : Volume $\left[\mathrm{m}^{3}\right]$

We: Weber number [-]

\section{Greek letters}


$\omega_{R}$ : Rotational speed of the rotor, $[\mathrm{rps}]$ in the equations, and $[\mathrm{rpm}]$ in table 2

$\beta$ : Coalescence kernel $\left[\mathrm{s}^{-1}\right]$

$\varepsilon$ : Energy dissipation rate $\left[\mathrm{W} \mathrm{kg}^{-1}\right]$

$\lambda$ : Coalescence efficiency $[-]$

$\mu$ : Viscosity [Pa.s]

$\rho$ : Density $\left[\mathrm{kg} \mathrm{m}^{-3}\right]$

$\sigma:$ Interfacial tension $\left[\mathrm{N} \mathrm{m}^{-1}\right]$

$\phi$ : Volume fraction $[-]$

\section{Subscripts}

Br: Breakage

c: Continues phase

Co: Coalescence

$\mathrm{d}$ : Dispersed phase (single emulsion)

disp: Dispersed phase (multiple emulsion)

eff: effective

Leak: Leakage

m: Micro-droplet

M: Macro-droplet

\section{References}

[1] W. Seifriz, Studies in Emulsions. I-II, J. Phys. Chem. 29 (1924) 587-600. doi:10.1021/j150251a008.

[2] W.S.W. Ho, K.K. Sirkar, eds., Membrane Handbook, Springer US, Boston, MA, 1992. doi:10.1007/978-1-4615-3548-5.

[3] G. Muschiolik, Multiple emulsions for food use, Curr. Opin. Colloid Interface Sci. 12 (2007) 213-220. doi:10.1016/j.cocis.2007.07.006. 
[4] A. Aserin, ed., Multiple emulsions: technology and applications, Wiley-Interscience, Hoboken, N.J, 2008.

[5] F. Wolf, L. Hecht, H.P. Schuchmann, E.H. Hardy, G. Guthausen, Preparation of $W_{1} / O / W_{2}$ emulsions and droplet size distribution measurements by pulsed-field gradient nuclear magnetic resonance (PFG-NMR) technique, Eur. J. Lipid Sci. Technol. 111 (2009) 730-742. doi:10.1002/ejlt.200800272.

[6] T. Schmidts, D. Dobler, C. Nissing, F. Runkel, Influence of hydrophilic surfactants on the properties of multiple W/O/W emulsions, J. Colloid Interface Sci. 338 (2009) 184-192. doi:10.1016/j.jcis.2009.06.033.

[7] S. Matsumoto, Y. Kita, D. Yonezawa, An attempt at preparing water-in-oil-in-water multiple-phase emulsions, J. Colloid Interface Sci. 57 (1976) 353-361. doi:10.1016/00219797(76)90210-1.

[8] L. Zeng, Y. Zhang, C. Bukirwa, W. Li, Y. Yang, Study of mean diameter and drop size distribution of emulsion drops in a modified rotating disc contactor for an emulsion liquid membrane system, RSC Adv. 5 (2015) 89959-89970. doi:10.1039/C5RA16267J.

[9] J. Yan, R. Pal, Isotonic swelling behavior of W/O/W emulsion liquid membranes under agitation conditions, J. Membr. Sci. 213 (2003) 1-12. doi:10.1016/S0376-7388(02)00501-X.

[10] R.M. Pfeiffer, A.L. Bunge, W. Navidi, Leakage and Swell in Emulsion Liquid-Membrane Systems: Batch Experiments, Sep. Sci. Technol. 38 (2003) 519-539. doi:10.1081/SS120016649.

[11] S. Mukhopadhyay, S.K. Ghosh, V.A. Juvekar, Mathematical model for swelling in a liquid emulsion membrane system, Desalination. $232 \quad$ (2008) 110-127. doi:10.1016/j.desal.2008.01.009.

[12] S. Mataumoto, W.W. Kang, FORMATION AND APPLICATIONS OF MULTIPLE EMULSIONS, J. Dispers. Sci. Technol. 10 (1989) 455-482. doi:10.1080/01932698908943184.

[13] N. Jager-Lezer, I. Terrisse, F. Bruneau, S. Tokgoz, L. Ferreira, D. Clausse, M. Seiller, J.-L. Grossiord, Influence of lipophilic surfactant on the release kinetics of water-soluble molecules entrapped in a W/O/W multiple emulsion, J. Controlled Release. 45 (1997) 113. doi:10.1016/S0168-3659(96)01507-6.

[14] M. Chávez-Páez, C.M. Quezada, L. Ibarra-Bracamontes, H.O. González-Ochoa, J.L. ArauzLara, Coalescence in Double Emulsions, Langmuir. 28 (2012) 5934-5939. doi:10.1021/la205144g.

[15] R. Mezzenga, B.M. Folmer, E. Hughes, Design of Double Emulsions by Osmotic Pressure Tailoring, Langmuir. 20 (2004) 3574-3582. doi:10.1021/la036396k.

[16] A.J. Shere, H.M. Cheung, MODELING OF LEAKAGE IN LIQUID SURFACTANT MEMBRANE SYSTEMS, Chem. Eng. Commun. 68 (1988) 143-164. doi:10.1080/00986448808940403.

[17] J.T. Davies, Drop sizes of emulsions related to turbulent energy dissipation rates, Chem. Eng. Sci. 40 (1985) 839-842. doi:10.1016/0009-2509(85)85036-3.

[18] J.O. Hinze, Fundamentals of the hydrodynamic mechanism of splitting in dispersion processes, AIChE J. 1 (1955) 289-295. doi:10.1002/aic.690010303.

[19] J. Zhang, S. Xu, W. Li, High shear mixers: A review of typical applications and studies on power draw, flow pattern, energy dissipation and transfer properties, Chem. Eng. Process. Process Intensif. 57-58 (2012) 25-41. doi:10.1016/j.cep.2012.04.004. 
[20] P.J. Becker, F. Puel, R. Henry, N. Sheibat-Othman, Investigation of Discrete Population Balance Models and Breakage Kernels for Dilute Emulsification Systems, Ind. Eng. Chem. Res. 50 (2011) 11358-11374. doi:10.1021/ie2006033.

[21] Y. Liao, D. Lucas, A literature review on mechanisms and models for the coalescence process of fluid particles, Chem. Eng. Sci. 65 (2010) 2851-2864. doi:10.1016/j.ces.2010.02.020.

[22] T. Kataoka, T. Nishiki, Dispersed mean drop sizes of (W/O)/W emulsions in a stirred tank., J. Chem. Eng. Jpn. 19 (1986) 408-412. doi:10.1252/jcej.19.408.

[23] T. Ohtake, T. Hano, K. Takagi, F. Nakashio, Effects of viscosity on drop diameter of W/O emulsion dispersed in a stirred tank., J. Chem. Eng. Jpn. 20 (1987) 443-447. doi:10.1252/jcej.20.443.

[24] R. Rautenbach, O. Machhammer, Modeling of liquid membrane separation processes, J. Membr. Sci. 36 (1988) 425-444. doi:10.1016/0376-7388(88)80034-6.

[25] T. Gallego-Lizon, E.S. Pérez de Ortiz, Drop Sizes in Liquid Membrane Dispersions, Ind. Eng. Chem. Res. 39 (2000) 5020-5028. doi:10.1021/ie000016y.

[26] W.S. Ho, T.A. Hatton, E.N. Lightfoot, N.N. Li, Batch extraction with liquid surfactant membranes: A diffusion controlled model, AIChE J. 28 (1982) 662-670. doi:10.1002/aic.690280419.

[27] Z. Kang, P. Zhu, T. Kong, L. Wang, A Dewetting Model for Double-Emulsion Droplets, Micromachines. 7 (2016) 196. doi:10.3390/mi7110196.

[28] K. Pays, J. Giermanska-Kahn, B. Pouligny, J. Bibette, F. Leal-Calderon, Coalescence in Surfactant-Stabilized Double Emulsions, Langmuir. $17 \quad$ (2001) 7758-7769. doi:10.1021/la010735x.

[29] J.. Klahn, J.J.. Janssen, G.E.. Vaessen, R. de Swart, W.G.. Agterof, On the escape process during phase inversion of an emulsion, Colloids Surf. Physicochem. Eng. Asp. 210 (2002) 167-181. doi:10.1016/S0927-7757(02)00376-X.

[30] S. Okazaki, M. Imai, M. Shimizu, Leakage Suppressing Oe W/O Emulsion Using High Viscous Solvent, in: Process Metall., Elsevier, 1992: pp. 1487-1492. doi:10.1016/B978-0-44488677-4.50064-7.

[31] F. Michaut, P. Perrin, P. Hébraud, Interface Composition of Multiple Emulsions: Rheology as a Probe, Langmuir. 20 (2004) 8576-8581. doi:10.1021/la048715t.

[32] A. Sharma, A.N. Goswami, B.S. Rawat, Drop size prediction in liquid membrane systems, J. Membr. Sci. 60 (1991) 261-274. doi:10.1016/S0376-7388(00)81539-2.

[33] D. Ramkrishna, A.W. Mahoney, Population balance modeling. Promise for the future, Chem. Eng. Sci. 57 (2002) 595-606. doi:10.1016/S0009-2509(01)00386-4.

[34] D. Ramkrishna, Population balances: theory and applications to particulate systems in engineering, Academic Press, San Diego, CA, 2000.

[35] I. Lönnqvist, B. Håkansson, B. Balinov, O. Söderman, NMR Self-Diffusion Studies of the Water and the Oil Components in a W/O/W Emulsion, J. Colloid Interface Sci. 192 (1997) 66-73. doi:10.1006/jcis.1997.4966.

[36] J.P. Hindmarsh, J. Su, J. Flanagan, H. Singh, PFG-NMR Analysis of Intercompartment Exchange and Inner Droplet Size Distribution of W/O/W Emulsions, Langmuir. 21 (2005) 9076-9084. doi:10.1021/la051626b. 
[37] L. Boyadzhiev, T. Sapundzhiev, E. Bezenshek, Modeling of Carrier-Mediated Extraction, Sep. Sci. 12 (1977) 541-551. doi:10.1080/00372367708068466.

[38] Gustavo A. Padron, Measurement and comparison of power draw in batch rotor-stator mixers, Doctoral dissertation, University of Maryland, 2001.

[39] V. Alopaeus, J. Koskinen, K. I. Keskinen, J. Majander, Simulation of the population balances for liquid-liquid systems in a nonideal stirred tank. Part 2-parameter fitting and the use of the multiblock model for dense dispersions, Chem. Eng. Sci. 57 (2002) 1815-1825. doi:10.1016/S0009-2509(02)00067-2.

[40] C. Qin, C. Chen, Q. Xiao, N. Yang, C. Yuan, C. Kunkelmann, M. Cetinkaya, K. Mülheims, CFDPBM simulation of droplets size distribution in rotor-stator mixing devices, Chem. Eng. Sci. 155 (2016) 16-26. doi:10.1016/j.ces.2016.07.034.

[41] K.J. Valentas, O. Bilous, N.R. Amundson, Analysis of Breakage in Dispersed Phase Systems, Ind. Eng. Chem. Fundam. 5 (1966) 271-279. doi:10.1021/i160018a019.

[42] C.A. Coulaloglou, L.L. Tavlarides, Description of interaction processes in agitated liquidliquid dispersions, Chem. Eng. Sci. 32 (1977) 1289-1297. doi:10.1016/00092509(77)85023-9.

[43] M.A. Hsia, L.L. Tavlarides, A simulation model for homogeneous dispersions in stirred tanks, Chem. Eng. J. 20 (1980) 225-236. doi:10.1016/0300-9467(80)80007-4.

[44] P.M. Bapat, L.L. Tavlarides, G.W. Smith, Monte carlo simulation of mass transfer in liquidliquid dispersions, Chem. Eng. Sci. 38 (1983) 2003-2013. doi:10.1016/00092509(83)80104-3.

[45] C. Tsouris, L.L. Tavlarides, Breakage and coalescence models for drops in turbulent dispersions, AIChE J. 40 (1994) 395-406. doi:10.1002/aic.690400303.

[46] V. Alopaeus, J. Koskinen, K.I. Keskinen, Simulation of the population balances for liquidliquid systems in a nonideal stirred tank. Part 1 Description and qualitative validation of the model, Chem. Eng. Sci. 54 (1999) 5887-5899. doi:10.1016/S0009-2509(99)00170-0.

[47] Theodore Vermeulen, Interfacial area in liquid-liquid and gas-liquid agitation, Chem. Eng. Progr. 51 (1955) 85F-94F.

[48] S.A. Miller, C.A. Mann, Agitation of Two-Phase Systems of Immiscible Liquids, Trans. Am. Inst. Chem. Engrs. (1944) 709-743.

[49] F. Filbet, P. Laurençot, Numerical Simulation of the Smoluchowski Coagulation Equation, SIAM J. Sci. Comput. 25 (2004) 2004-2028. doi:10.1137/S1064827503429132.

[50] J. Kumar, G. Warnecke, M. Peglow, S. Heinrich, Comparison of numerical methods for solving population balance equations incorporating aggregation and breakage, Powder Technol. 189 (2009) 218-229. doi:10.1016/j.powtec.2008.04.014.

[51] G. Narsimhan, J.P. Gupta, D. Ramkrishna, A model for transitional breakage probability of droplets in agitated lean liquid-liquid dispersions, Chem. Eng. Sci. 34 (1979) 257-265. doi:10.1016/0009-2509(79)87013-X.

[52] M. Laakkonen, V. Alopaeus, J. Aittamaa, Validation of bubble breakage, coalescence and mass transfer models for gas-liquid dispersion in agitated vessel, Chem. Eng. Sci. 61 (2006) 218-228. doi:10.1016/j.ces.2004.11.066.

[53] M.M. Ribeiro, P.F. Regueiras, M.M.L. Guimarães, C.M.N. Madureira, J.J.C. Cruz_Pinto, Optimization of Breakage and Coalescence Model Parameters in a Steady-State Batch Agitated Dispersion, Ind. Eng. Chem. Res. 50 (2011) 2182-2191. doi:10.1021/ie100368t. 
[54] J. Jiao, D.J. Burgess, Rheology and stability of water-in-oil-in-water multiple emulsions containing Span 83 and Tween 80, AAPS PharmSci. 5 (2003) 62-73. doi:10.1208/ps050107. 
Table 1: Correlations for the release rate in double emulsions during preparation

\begin{tabular}{|c|c|}
\hline The release rate in double emulsions & Reference \\
\hline $\begin{array}{l}\text { Simple shear flow regime } \\
\frac{\mathrm{d} n_{\mathrm{m}}}{\mathrm{d} t}=\frac{-2 P}{t_{\mathrm{c}} \alpha_{\mathrm{cr}}}\left(n_{\mathrm{m}}-\left(1-\alpha_{\mathrm{cr}}\right) n_{\mathrm{m} 0}\right) \\
\text { Coalescence probability: } P=\left(\frac{\pi \sigma r_{\mathrm{m}}^{2}}{2 A_{H}}\right)^{-\frac{4}{9 \pi t_{c i r}}\left(1+\frac{\mu_{\mathrm{M}}}{\mu_{e x}}\right)} \\
\text { Volume fraction of critical region: } \alpha_{c r}=1-\exp \left(-\frac{r_{m}}{r_{M}}\left[2.22+1.51\left(\frac{\mu_{\mathrm{M}}}{\mu_{e x}}\right)^{-0.57}\right]\right) \\
\text { where } A_{H} \text { is Hamaker constant and } t_{c i r} \text { total circulation time }\end{array}$ & $\begin{array}{l}\text { Klahn et al. } \\
(2002) \text { [29] }\end{array}$ \\
\hline $\begin{array}{l}\text { Turbulent regime in core-shell morphology } \\
\frac{\mathrm{d} \theta}{\mathrm{d} t}=K_{\mathrm{Br}}(1-\theta) \\
\theta=\frac{\left(C_{\mathrm{ex}}(t)-C_{\mathrm{ex}}\left(t_{0}\right)\right) V_{\mathrm{ex}}}{C_{\mathrm{m}} V_{\mathrm{m}}} \\
\left\{\begin{array}{l}K_{\mathrm{Br}}=3 \times 10^{-19} \delta^{-1} \mu_{\mathrm{M}}^{-0.8} \varepsilon^{\left(2.2 \times 10^{-8} \Delta \Pi+0.8\right)} \Delta \Pi^{0.9}, \Delta \Pi>1 \times 10^{6} \\
K_{\mathrm{Br}}=8 \times 10^{-13} \delta^{-1} \mu_{\mathrm{M}}^{-0.8} \varepsilon^{0.8} \quad, \Delta \Pi<1 \times 10^{6}\end{array}\right. \\
\text { Where } \Pi \text { is osmotic pressure and } \delta=r_{m}\left(\phi_{m}^{-1 / 3}-1\right) \text { is the membrane thickness. }\end{array}$ & $\begin{array}{l}\text { Okazaki et al. } \\
(1992)[30]\end{array}$ \\
\hline $\begin{array}{l}\text { Turbulent regime } \\
\ln \left(\frac{n_{\mathrm{M}}(t)}{n_{\mathrm{M}}\left(t_{\mathrm{f}}\right)}\right)=\ln \left(\frac{n_{\mathrm{M}}\left(t_{0}\right)}{n_{\mathrm{M}}\left(t_{\mathrm{f}}\right)}\right) e^{-k t} \\
\ln \left(\frac{L\left(t_{\mathrm{f}}\right)}{L(t)}\right)=a_{\mathrm{m}} \ln \left(\frac{n_{\mathrm{M}}\left(t_{\mathrm{f}}\right)}{n_{\mathrm{M}}\left(t_{0}\right)}\right) e^{-\left(k_{\mathrm{m}}+k\right) t} \\
L=\frac{\left(C_{e x}(t)-C_{e x}\left(t_{0}\right)\right)\left(1-\phi_{m}\right) 100}{C_{\mathrm{in} \phi_{m} \phi_{M}}} \text { is the leakage fraction and } k, k_{\mathrm{m}} \text { and } a_{\mathrm{m}} \text { are constants }\end{array}$ & $\begin{array}{l}\text { Shere \& Cheung } \\
(1988)[16]\end{array}$ \\
\hline
\end{tabular}


Table 2: Experimental conditions

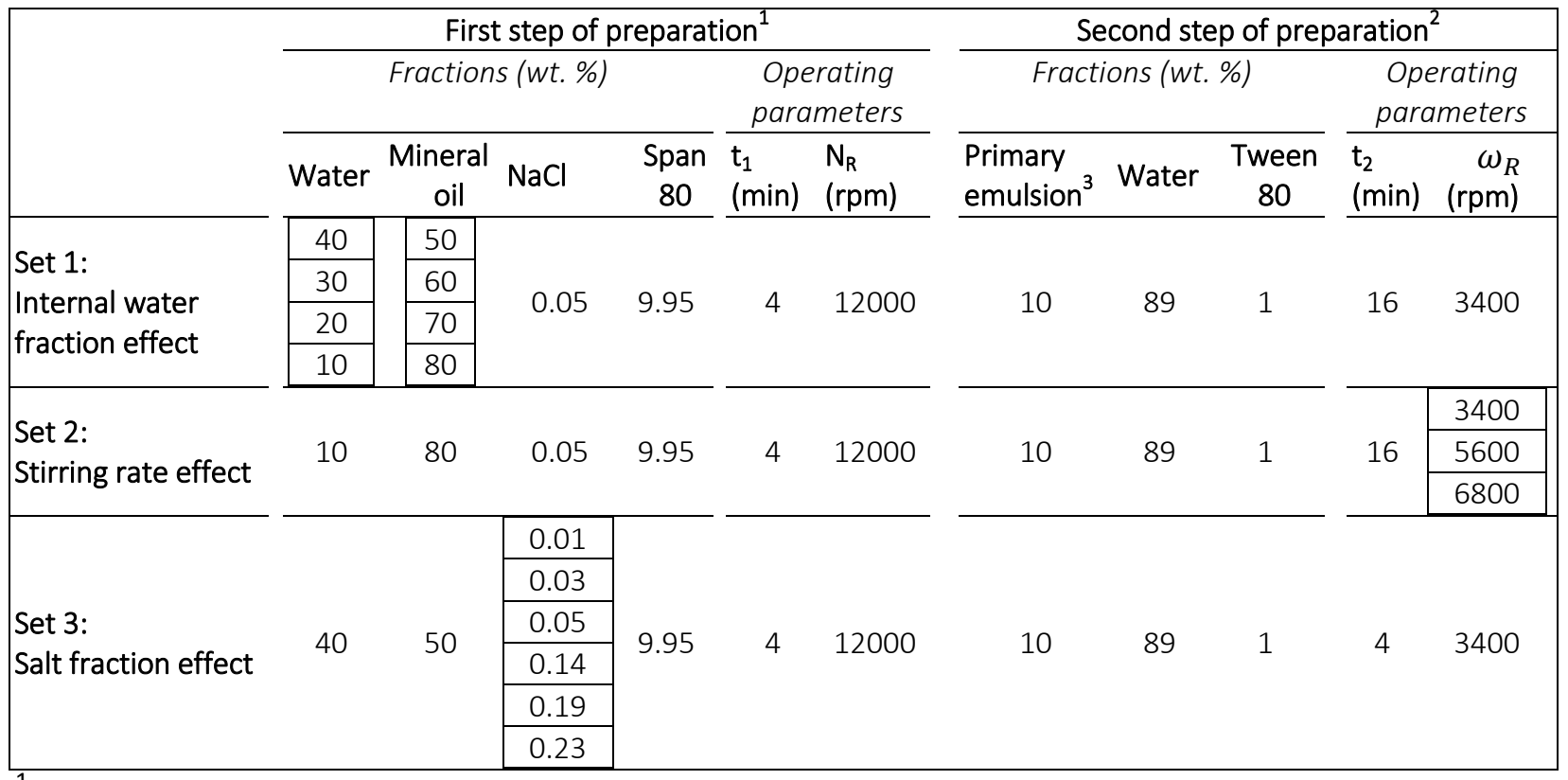

${ }^{1}$ These values are weight percentages of the total first step (primary, or internal emulsion)

${ }^{2}$ These values are weight percentages of the total double emulsion

${ }^{3}$ The primary emulsion consists of the emulsion produced in the first step

The total volume is $250 \mathrm{ml}$ 
Table 3: Identified parameters for the different models compared to literature values

\begin{tabular}{|c|c|c|c|c|c|c|c|c|c|}
\hline \multicolumn{3}{|c|}{ Breakage } & \multicolumn{2}{|c|}{ Coalescence } & \multirow{2}{*}{$\begin{array}{c}\text { Leakage } \\
\mathrm{K}_{\mathrm{L}} \\
\text { (m) }\end{array}$} & \multicolumn{2}{|c|}{$K_{L}$ model (eq. 26) } & \multirow[t]{2}{*}{ Geometry } & \multirow[t]{2}{*}{ Ref. } \\
\hline $\begin{array}{c}\mathrm{C}_{1} \\
\left(\mathrm{~m}^{-2 / 3}\right)\end{array}$ & $\mathrm{C}_{2}$ & $C_{3}$ & $\mathrm{C}_{4}$ & $\begin{array}{c}\mathrm{C}_{5} \\
\left(\mathrm{~m}^{-2}\right)\end{array}$ & & $\begin{array}{l}\mathrm{K}_{\mathrm{LO} 0} \\
(\mathrm{~m})\end{array}$ & $\alpha$ & & \\
\hline 0.719 & $3.76 \times 10^{-5}$ & 0.0018 & 0.913 & 5.66 & $1.74 \times 10^{-9}$ & $8.77 \times 10^{-6}$ & 2.54 & Ultraturrax & $\begin{array}{l}\text { This } \\
\text { work }\end{array}$ \\
\hline & & & $1.5 \times 10^{-4}$ & $1.83 \times 10^{13}$ & & & & Stirred tank & {$[42]$} \\
\hline 0.986 & $8.92 \times 10^{-4}$ & 0.2 & $4.33 \times 10^{-4}$ & & & & & Stirred tank & [39] \\
\hline 6 & 0.04 & 0.01 & 4.6 & $6 \times 10^{9}$ & & & & Stirred tank & {$[52]$} \\
\hline 0.657 & 0.021 & 0.402 & $2.3 \times 10^{-6}$ & $1.2 \times 10^{9}$ & & & & Stirred tank & {$[20]$} \\
\hline & & & $\begin{array}{c}3.6 \times 10^{-4} \\
\text { to } \\
9.2 \times 10^{-4}\end{array}$ & $\begin{array}{c}12.5 \text { to } \\
640\end{array}$ & & & & Stirred tank & [53] \\
\hline
\end{tabular}


Figure 1: Double emulsion preparation by the two-step method.

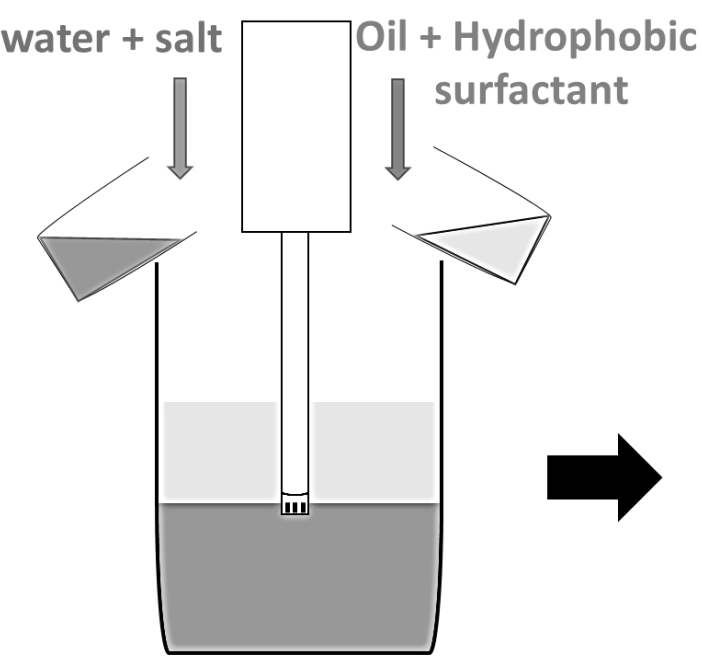

$1^{\text {st }}$ Step

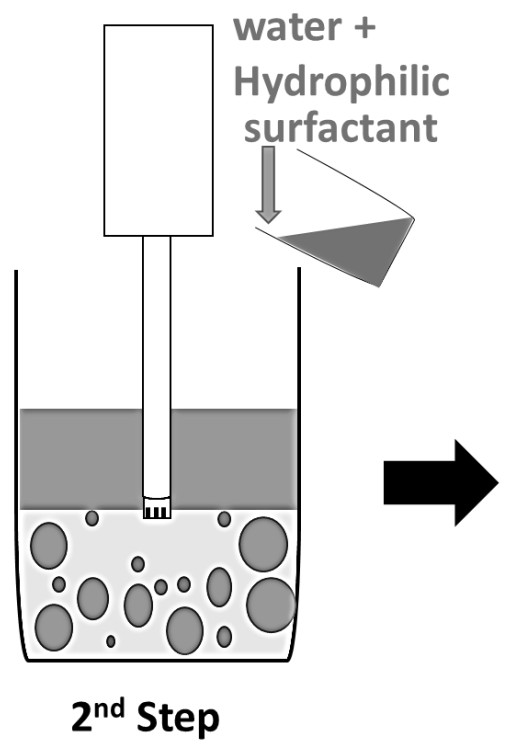


Figure 2: Optical microscopic image of the double emulsion taken just after preparation, with two different zooms $\left(\phi_{m}=40 \%, 3400 \mathrm{rpm}, \phi_{M}=10 \%, 2^{\text {nd }}\right.$ step mixing time $=4 \mathrm{~min}$ )

A

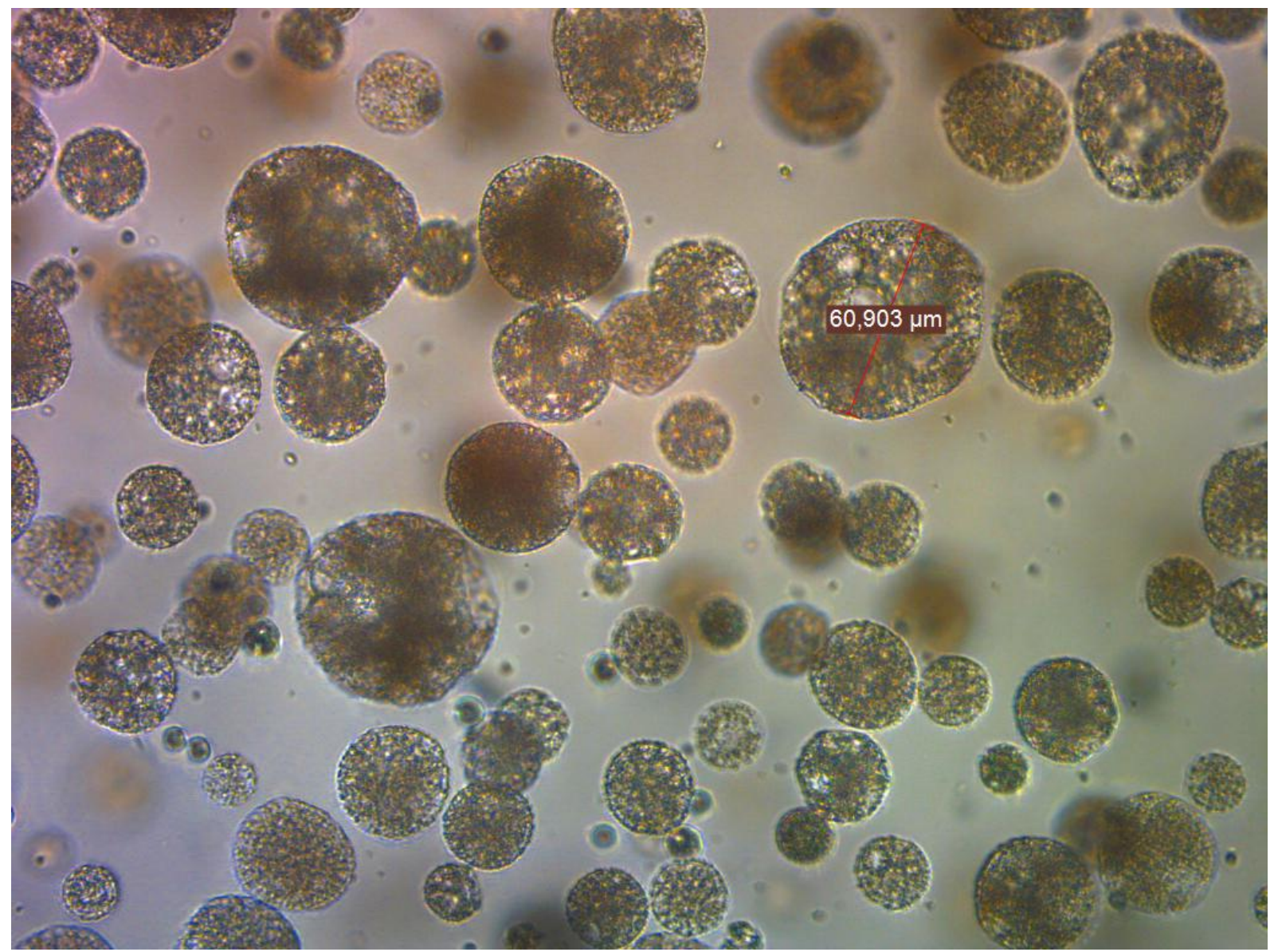


Figure 2: Optical microscopic image of the double emulsion taken just after preparation, with two different zooms $\left(\phi_{m}=40 \%, 3400 \mathrm{rpm}, \phi_{M}=10 \%, 2^{\text {nd }}\right.$ step mixing time $=4 \mathrm{~min}$ )

B

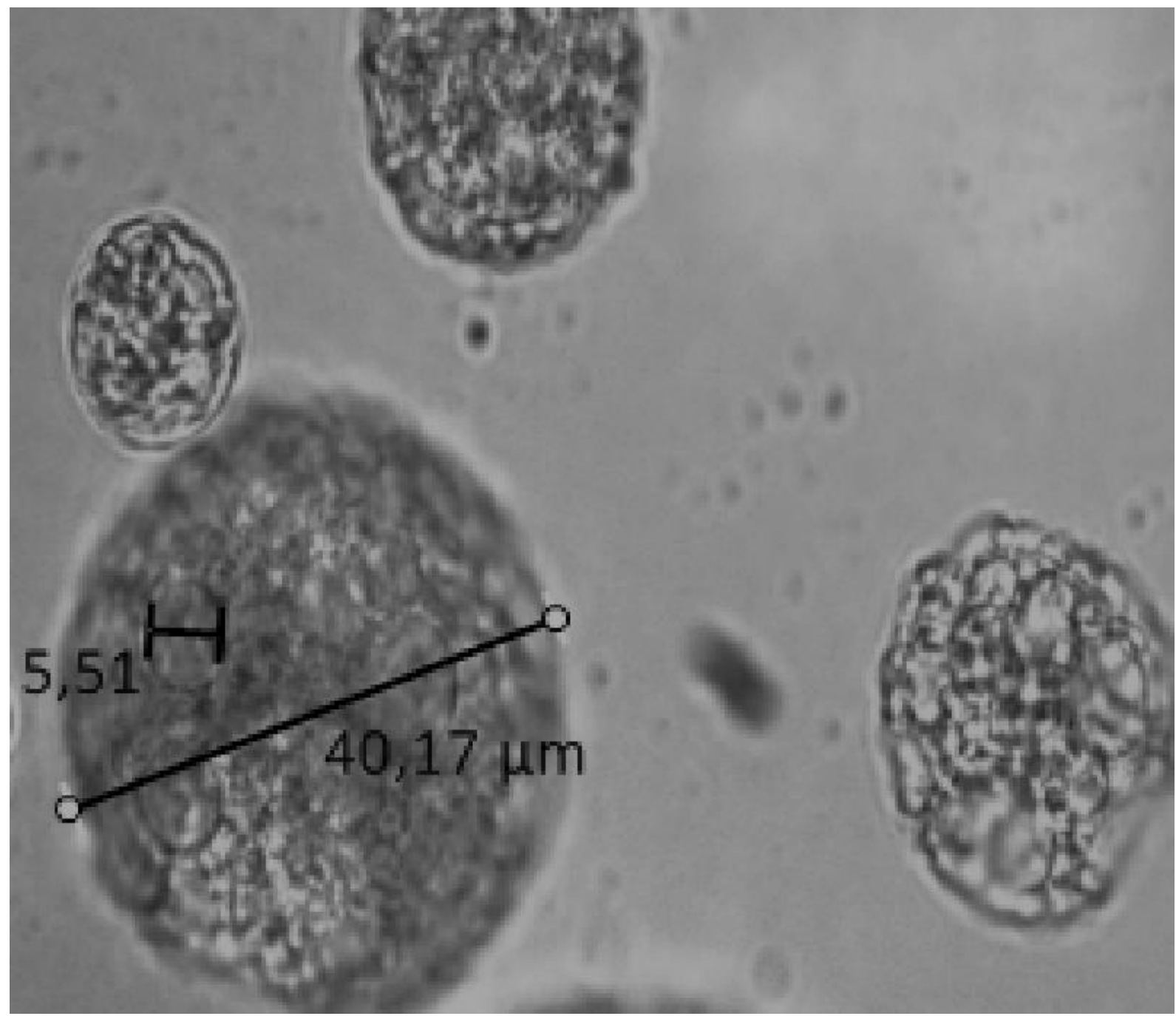


Figure 3: Example of the droplet size distribution of micro-droplets measured by NanoZS.

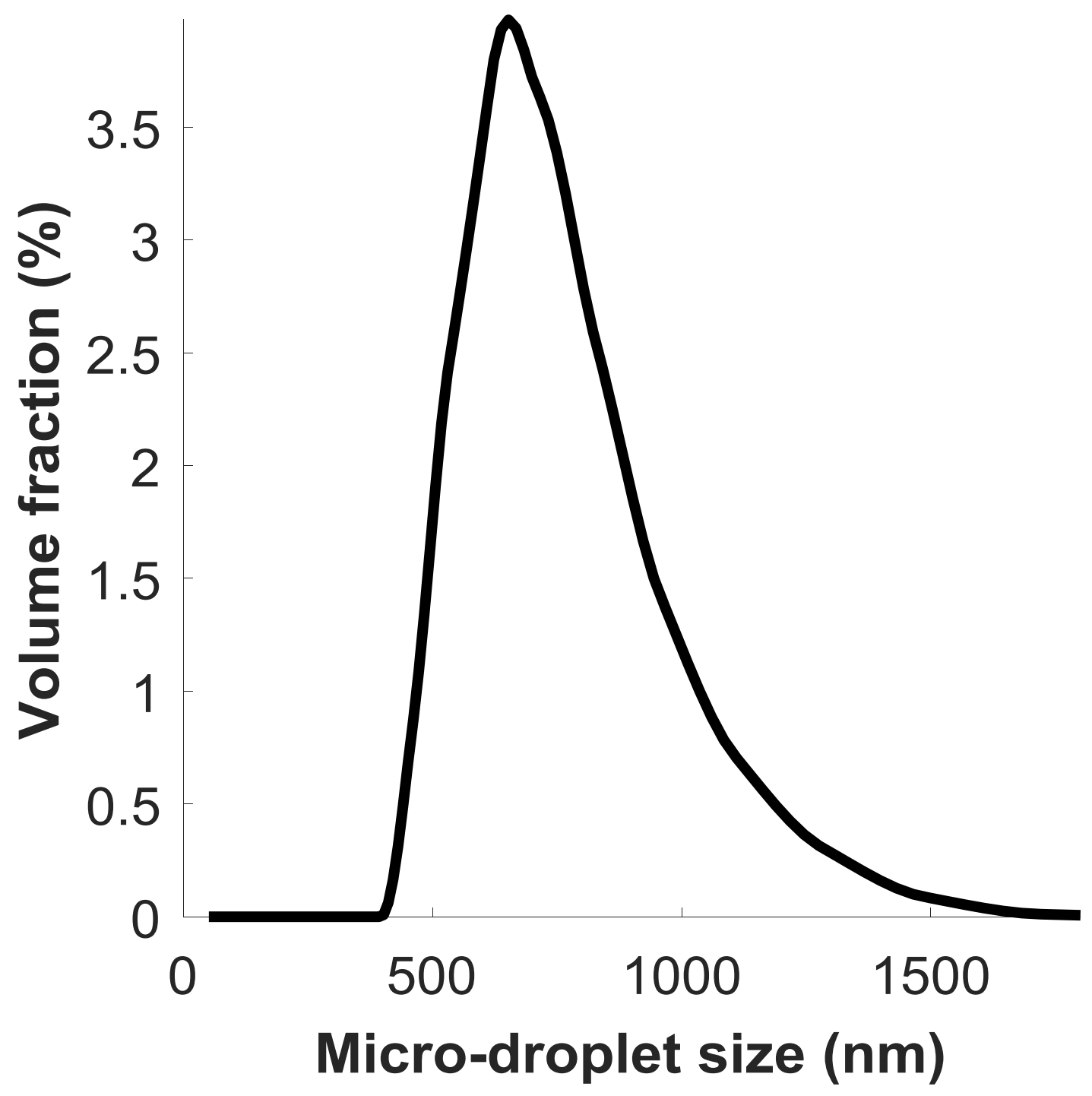


Figure 4: Experimental and modelling results for $\phi_{m}=40 \%, \phi_{M}=10 \%, 3400 \mathrm{rpm}$, showing (A) the macro-DSD, and $(B)$ the leakage rate.

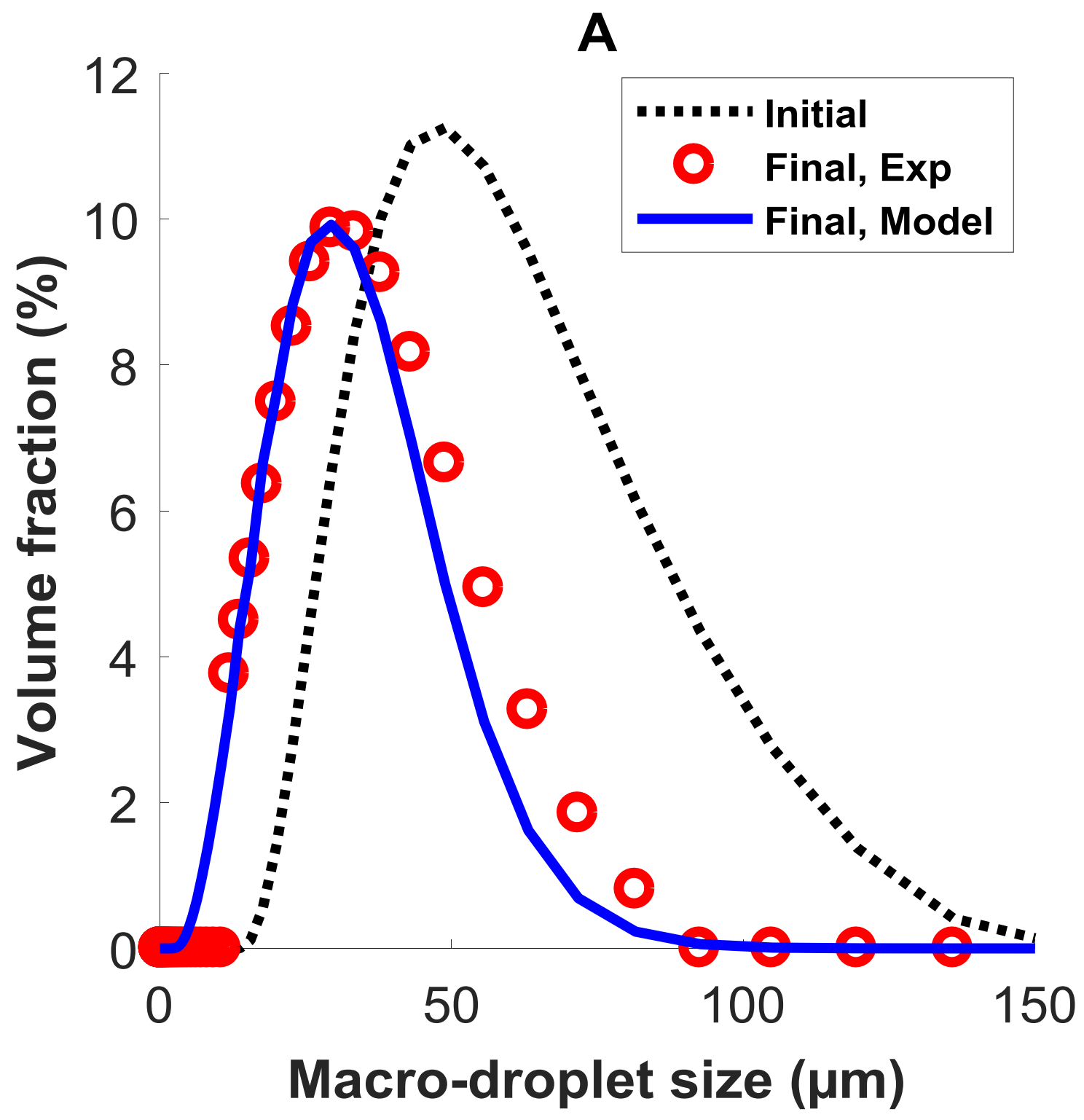


Figure 4: Experimental and modelling results for $\phi_{m}=40 \%, \phi_{M}=10 \%, 3400 \mathrm{rpm}$, showing (A) the macro-DSD, and $(B)$ the leakage rate.

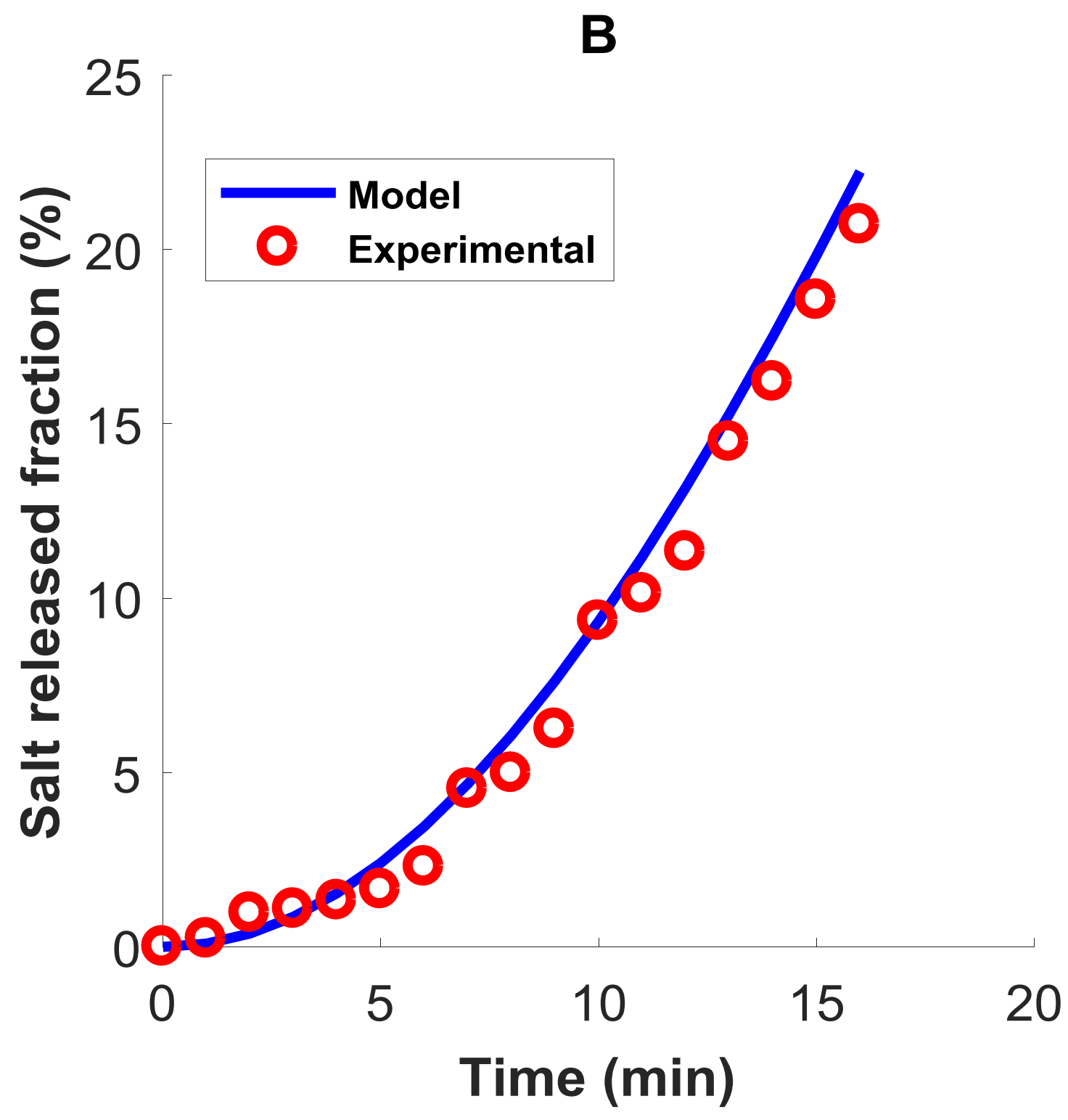


Figure 5: Effect of the internal water fraction, in the experiments of set 1, on $(A)$ the evolution of macro-DSD, and (B) the leakage of salt. The lines indicate the model predications and the symbols the experimental results.

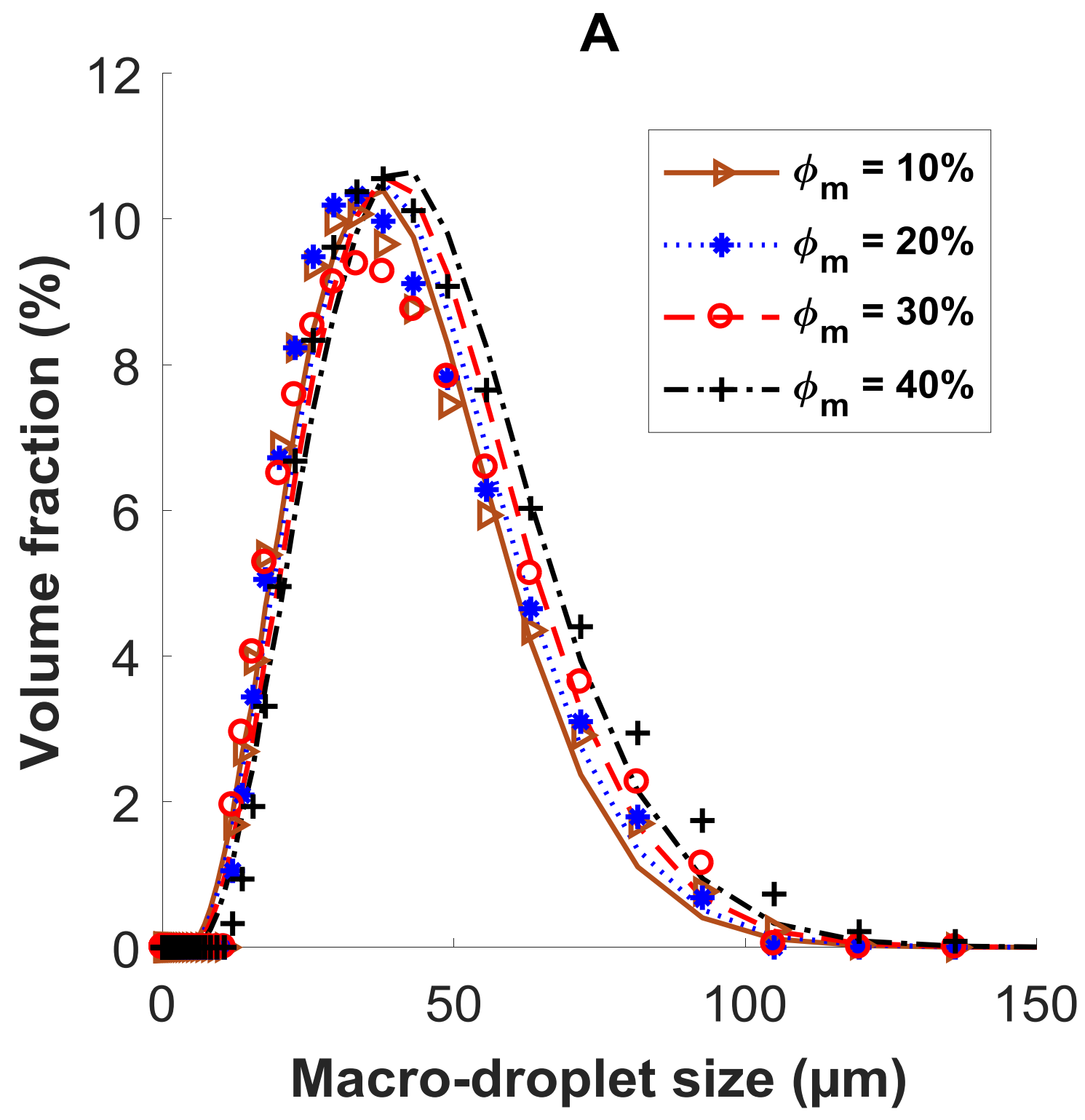

Figure 5: Effect of the internal water fraction, in the experiments of set 1, on $(A)$ the evolution of macro-DSD, and (B) the leakage of salt. The lines indicate the model predications and the symbols the experimental results. 


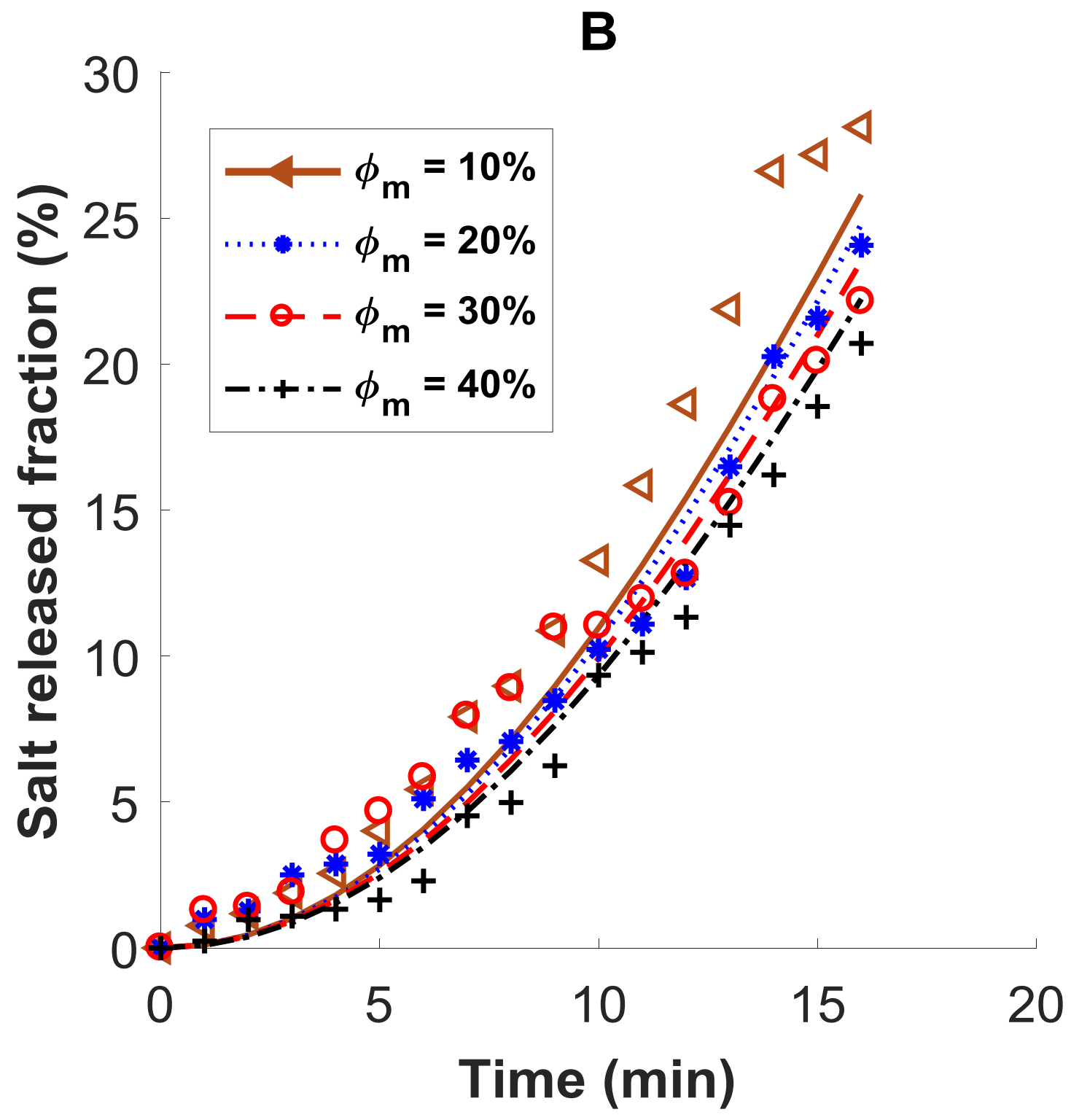


Figure 6: Effect of energy dissipation rate, in the experiments of set 3, on (A) the evolution of macro-DSD, and $(B)$ salt leakage. The lines indicate the model predications and the symbols the experimental results.

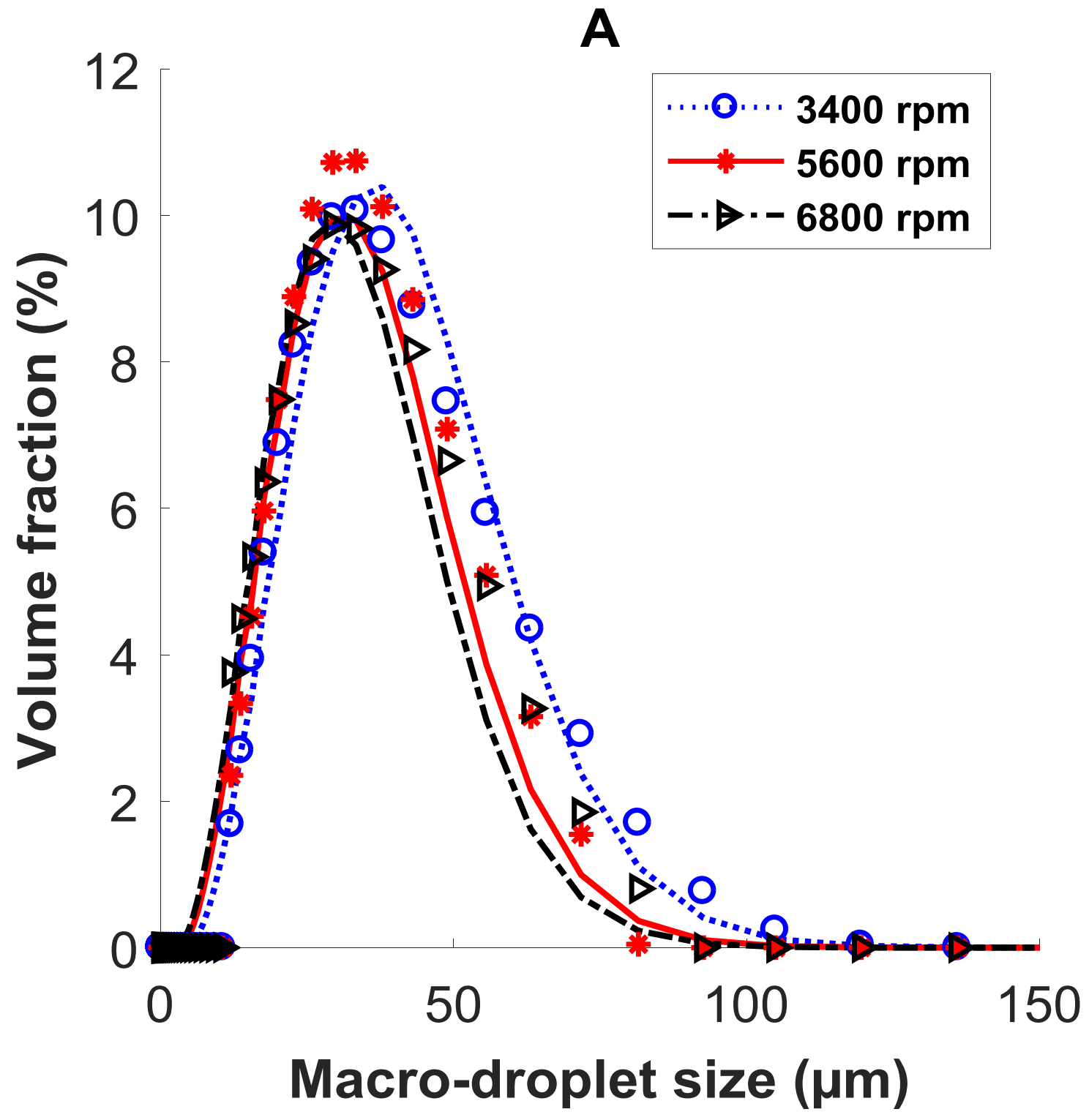


Figure 6: Effect of energy dissipation rate, in the experiments of set 3, on (A) the evolution of macro-DSD, and $(B)$ salt leakage. The lines indicate the model predications and the symbols the experimental results.

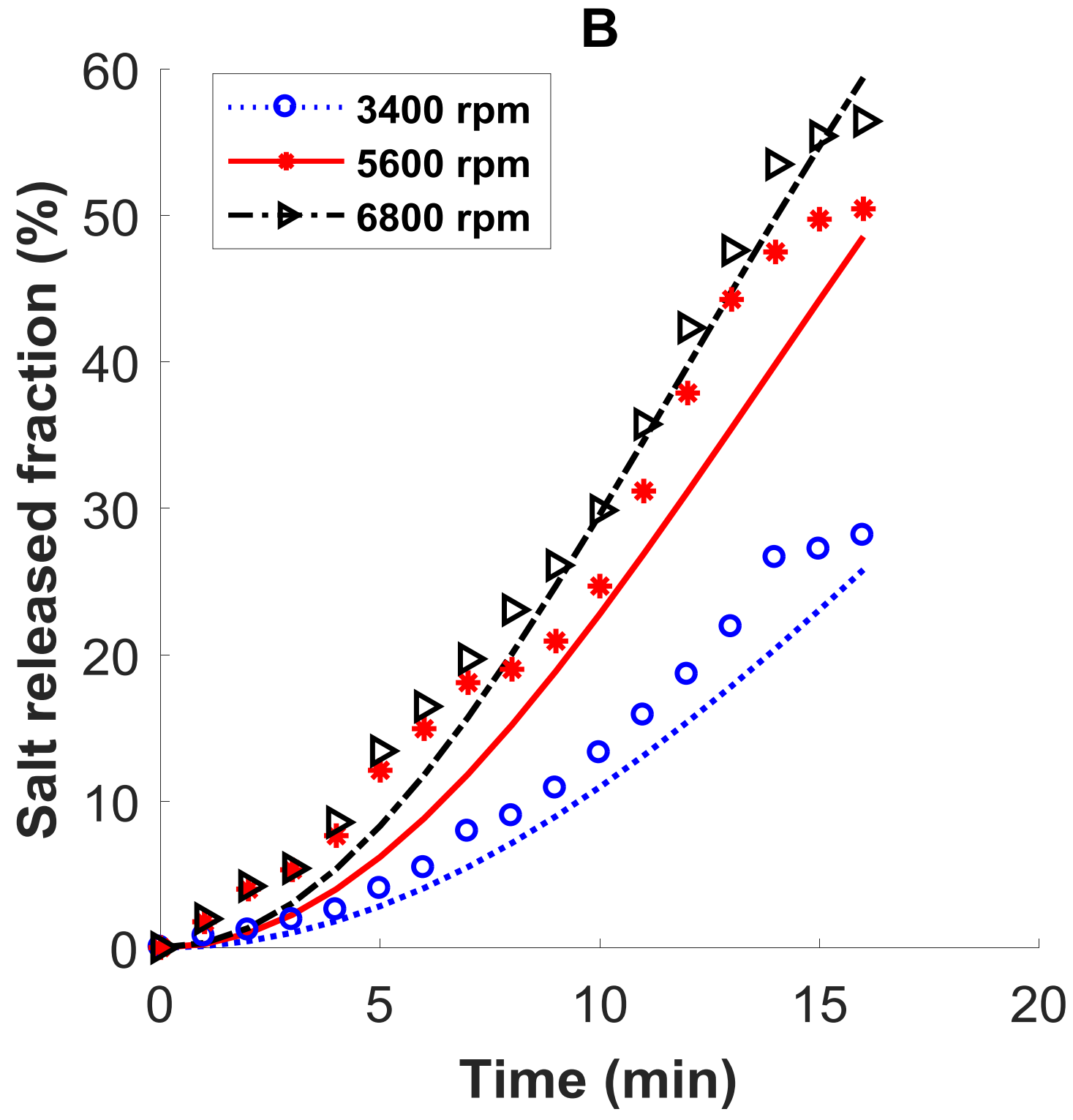


Figure 7: Evolution of the macro-DSD with time ( $\phi_{m}=10 \%$ ) (A) at $3400 \mathrm{rpm}$ (Exp. 1.3) and (B) $5600 \mathrm{rpm}$ (Exp. 2.2). The lines indicate the model predications and the symbols the experimental results.

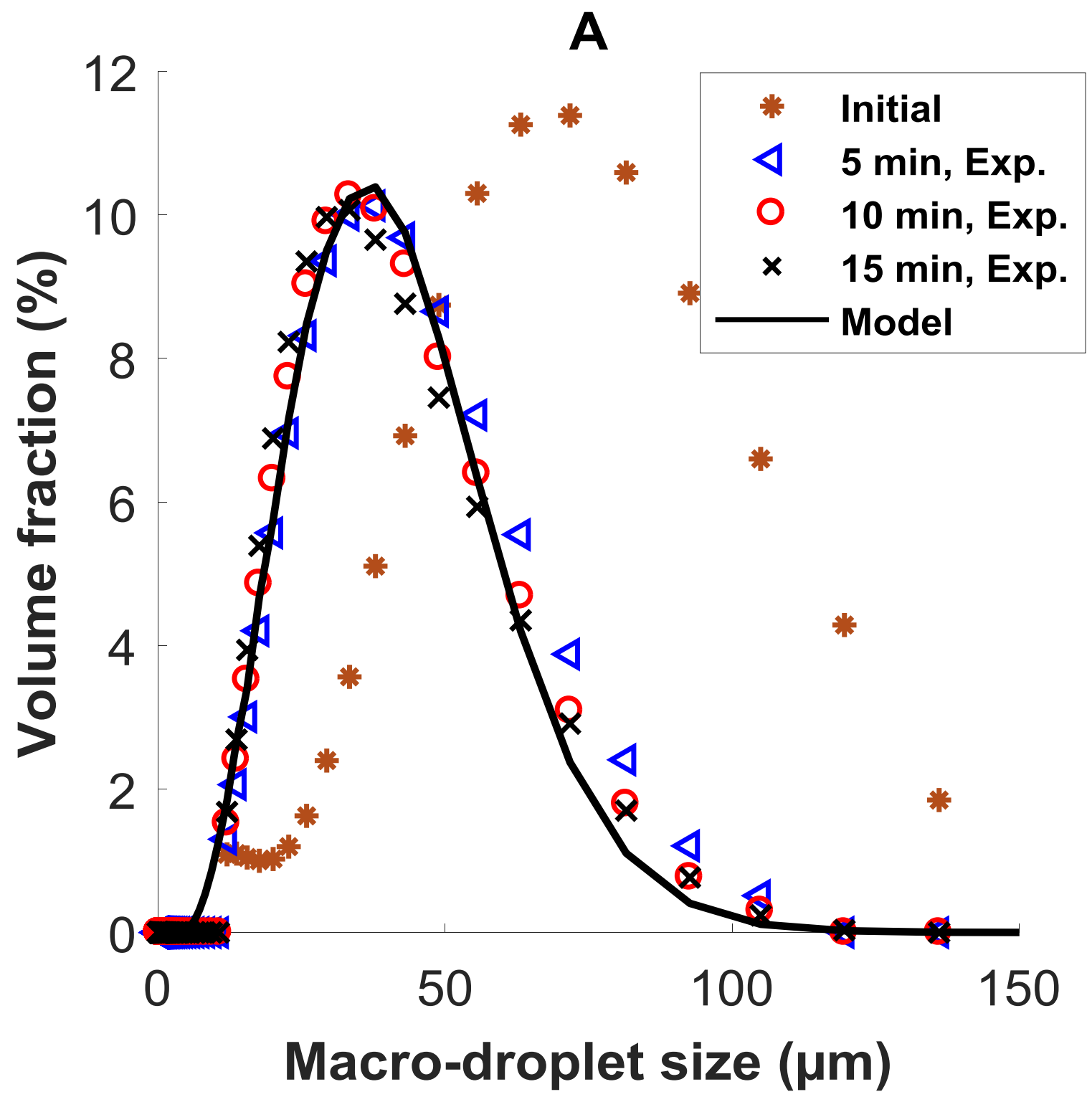


Figure 7: Evolution of the macro-DSD with time ( $\phi_{m}=10 \%$ ) (A) at $3400 \mathrm{rpm}$ (Exp. 1.3) and (B) $5600 \mathrm{rpm}$ (Exp. 2.2). The lines indicate the model predications and the symbols the experimental results.

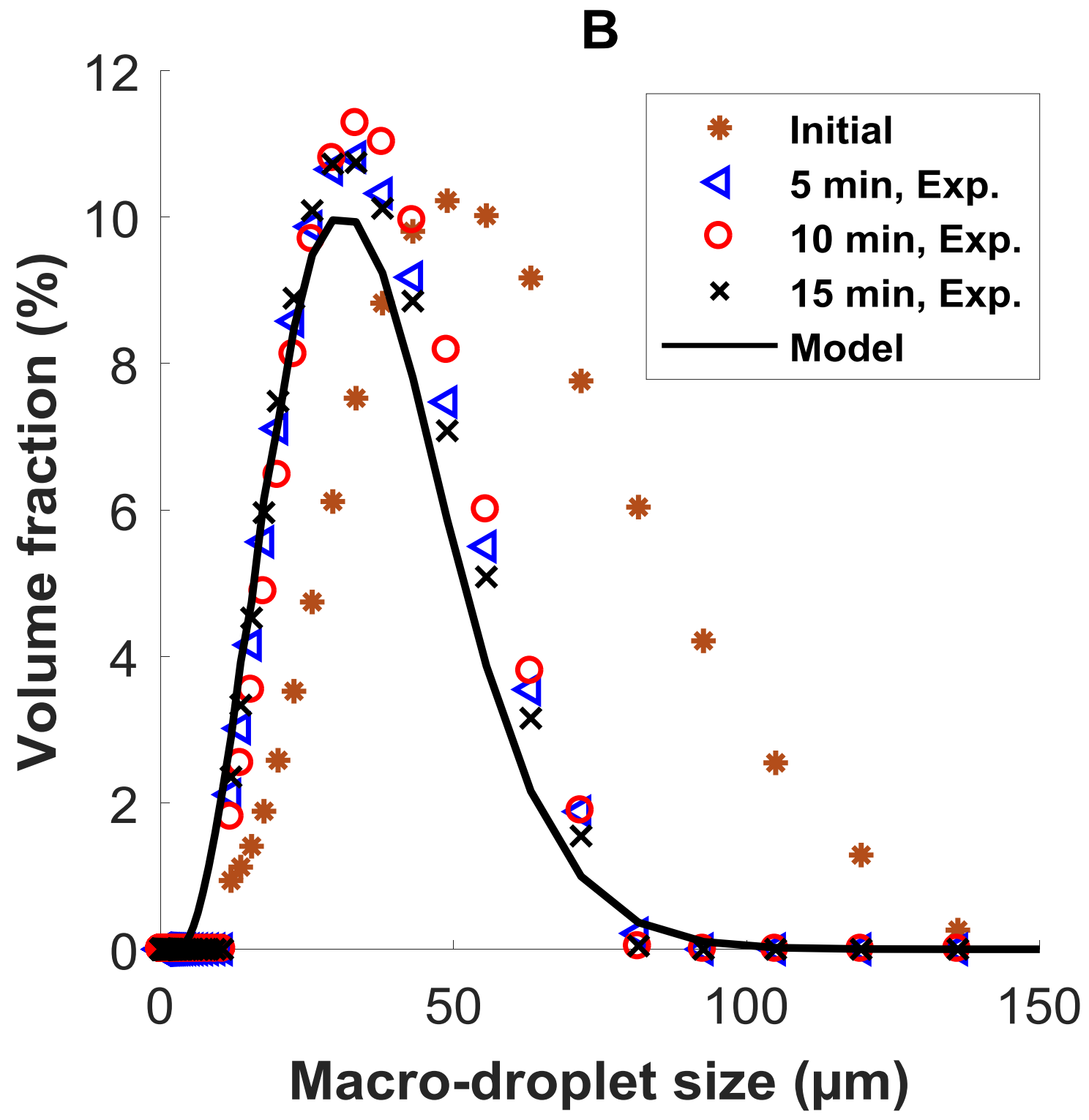


Figure 8: Effect of the initial salt concentration on (A) the leakage rate during the second step of preparation, the dashed line is the model (Equation 25), and (B) on the DSD of micro-droplets.

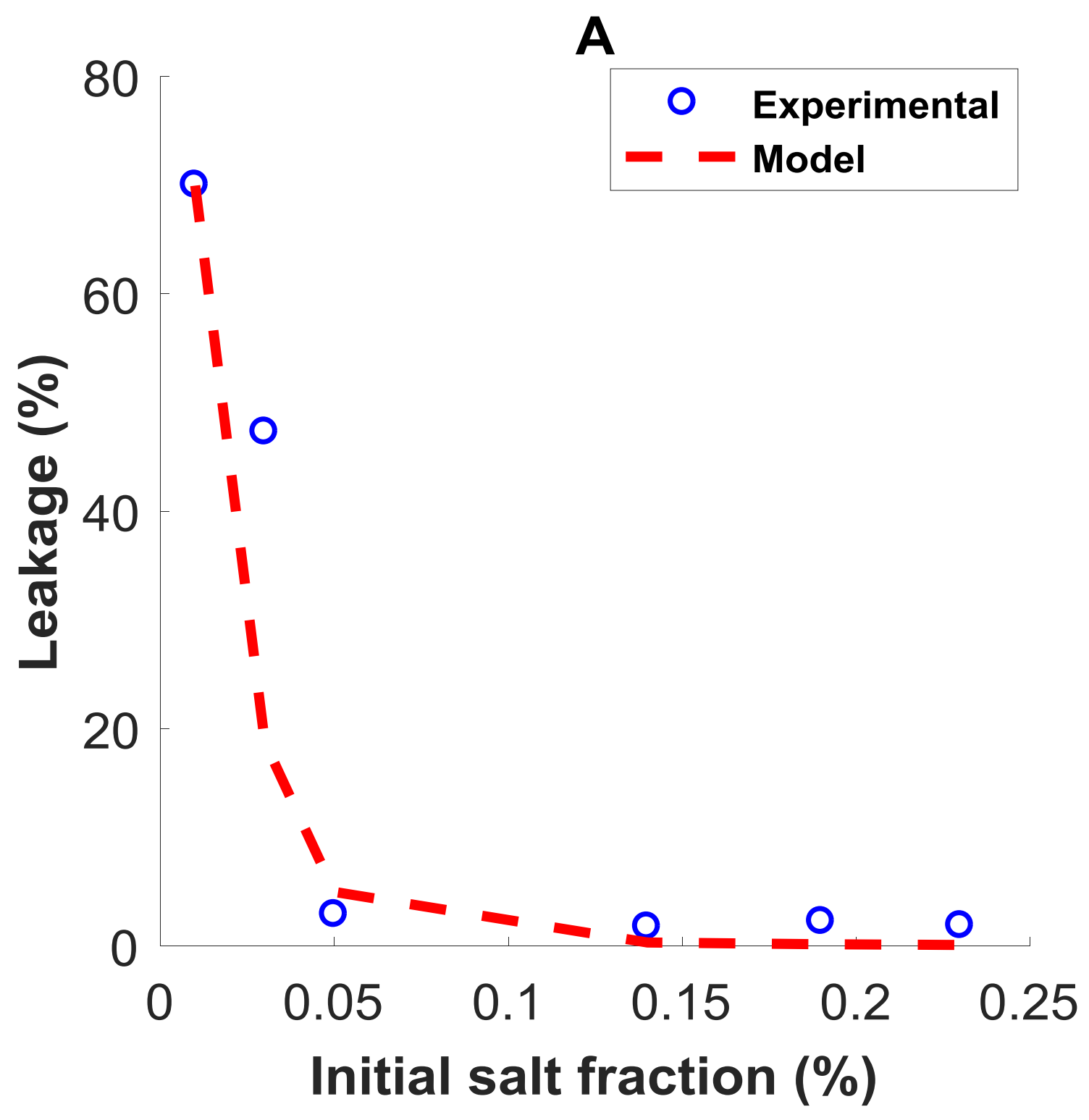


Figure 8: Effect of the initial salt concentration on (A) the leakage rate during the second step of preparation, the dashed line is the model (Equation 25), and (B) on the DSD of micro-droplets.

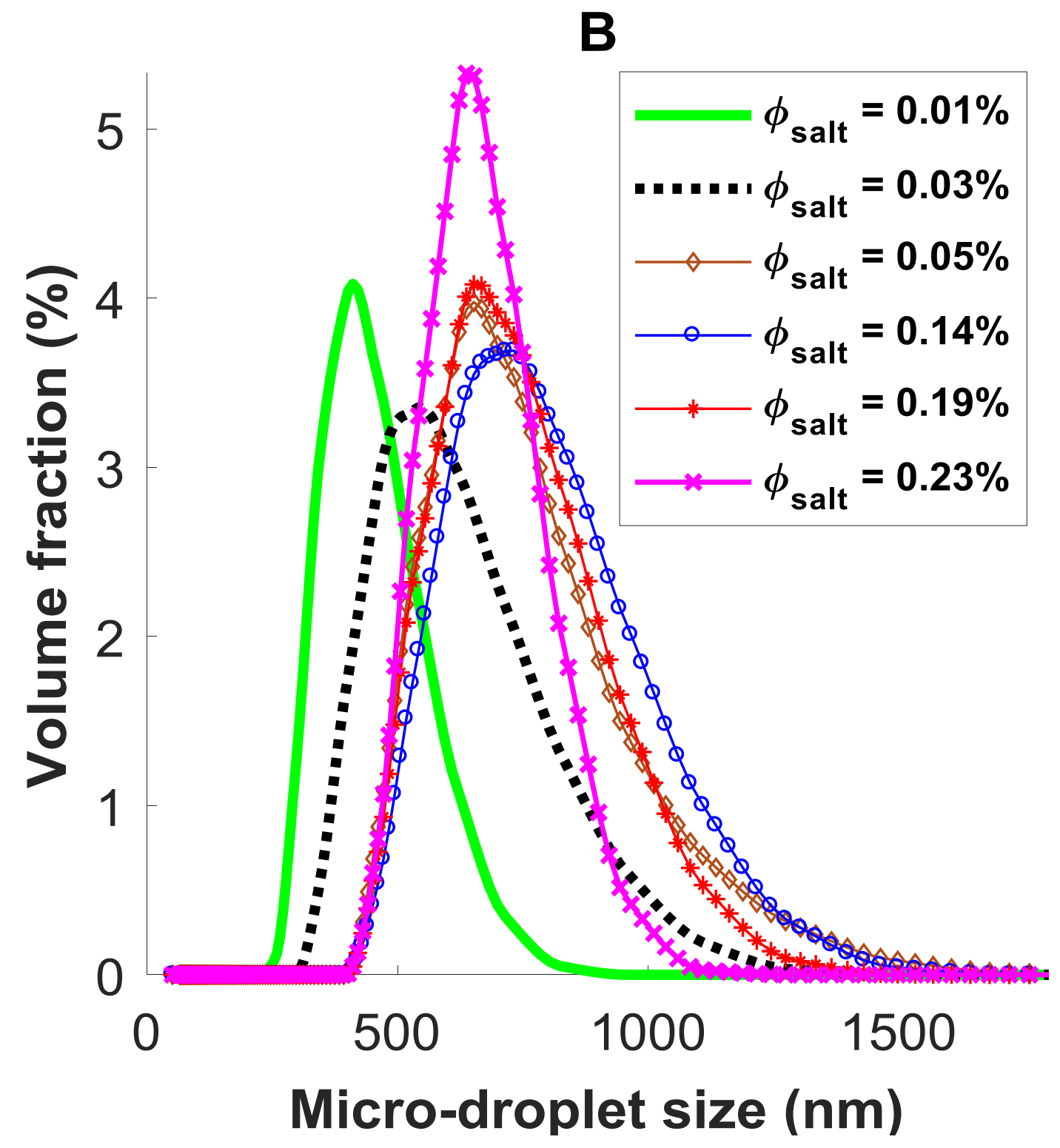


Figure 9: Relation between the $d_{32}$ of macro-droplets (experimental and using PBM) and the Weber number

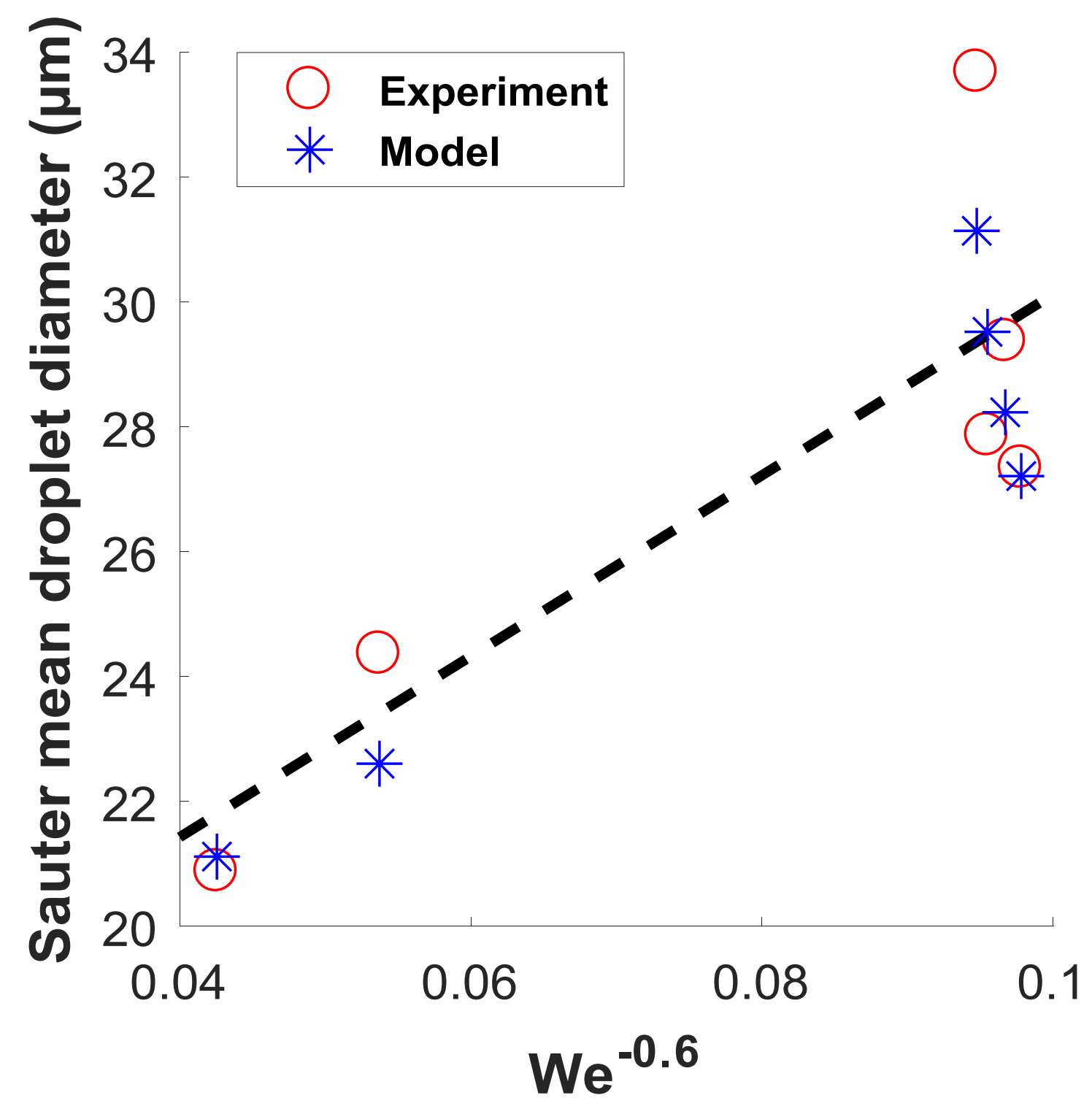

